\title{
Direct and Indirect Negative Ties and Individual Performance
}

\author{
Joshua E. Marineau \\ Assistant Professor of Management \\ College of Business \\ North Dakota State University \\ Fargo, ND 58108 \\ joshua.marineau@ndsu.edu \\ (859) 312-2875 \\ Giuseppe (Joe) Labianca \\ Gatton Chair in Management \\ Gatton College of Business \& Economics \\ LINKS Center for Social Network Analysis \\ University of Kentucky \\ and \\ Gerald C. Kane \\ Associate Professor of Information Systems \\ Carroll School of Management \\ Boston College
}

\begin{abstract}
We argue and find that negative ties are not always liabilities to workplace performance. Instead, negative ties can be beneficial depending on how socially distant they are from the person (i.e., whether they are direct or indirect negative ties), and how those ties are embedded with other ties. Results from a field study at a large life sciences company show that an employee's number of direct negative ties is related to poorer performance, as rated by that individual's supervisor. However, indirect negative ties can either be beneficial or liabilities to performance, depending on whether they are embedded in "open" or "closed" triadic structures.
\end{abstract}

Key words: social networks, negative ties, performance, social distance, embeddedness, social exchange

Correspondence concerning this paper should be addressed to Joshua Marineau, Department of Management and Marketing, North Dakota State University, Fargo, ND 58102. E-mail: joshmarineau@gmail.com; (859) 312-2875 
Direct and Indirect Negative Ties and Individual Performance 
Research in the social network tradition argues that individuals' social relationships, or ties, provide them both opportunities and constraints in accessing valuable resources such as trust, knowledge, information, power, and social and political support (S Borgatti \& Foster, 2003; SP Borgatti, Mehra, Brass, \& Labianca, 2009; Brass, 1984; Brass, Galaskiewicz, Greve, \& Tsai, 2004). Of increasing interest in relating social network benefits and liabilities to outcomes has been the importance of negative ties - relationships in which at least one person has enduring, recurring negative feelings and/or behavioral intentions toward another (G. Labianca \& Brass, 2006; G. J. Labianca, 2014). Negative tie research has largely focused on individuals’ direct, dyadic experience with negative relationships, including dealing with extended relationship conflict, negative gossip, social exclusion, and interpersonal dislike (Duffy, Ganster, \& Pagon, 2002; Ellwardt, Labianca, \& Wittek, 2011; G. Labianca \& Brass, 2006). Directly experiencing negative ties has been linked to a broad range of behavioral, physical, and psychological strains such as depression, life dissatisfaction, and reduced psychological wellbeing (e.g., Hirsch \& Rapkin, 1986; Pagel, Erdly, \& Becker, 1987; Rook, 1984). Negative relationships are also related to organizationally relevant outcomes such as lower individual performance, decreased satisfaction with one's group, and lower organizational attachment (e.g., Baldwin, Bedell, \& Johnson, 1997; Sparrowe, Liden, Wayne, \& Kraimer, 2001; Vijaya Venkataramani, Labianca, \& Grosser, 2013). The predominant theme of this research is that negative ties relate to a diverse set of liabilities for individuals. Yet most of this empirical research has focused on the situation where someone is directly involved in a negative tie with another person. What is lacking is a perspective emphasizing that negative relationships can sometimes create positive externalities for other people in the network who are not directly involved in the negative relationship - that is, that indirect negative ties can sometimes be 
beneficial for individuals.

We draw on balance theory (Cartwright \& Harary, 1956; F. Heider, 1958) and powerdependence exchange theory (e.g., Cook, Emerson, Gillmore, \& Yamagishi, 1983; R. M. Emerson, 1972) to examine when indirect negative ties are related to benefits or liabilities in terms of supervisor-rated performance in a workplace setting. We argue that some network positions, such as “closed triads," can create performance liabilities for a focal individual (ego). We define closed triads as where three persons each have a tie to others in the triad (i.e., they are transitive). We specifically consider two special cases of closed triads which contain either direct or indirect negative ties from the perspective of the focal individual. First, we consider triads where ego has two positive ties (alters) who are themselves involved in a negative tie; this places ego in the difficult position of being stuck in between two opposing alters (see Figure 1a), which can be a source of psychological and relational liabilities (Coser, 1956; Newcomb, 1968; Simmel, 1950, 1955; Zajonc, 1960). Second, we consider triads where ego has two negative tie alters who are themselves positively tied (see Figure 1b), placing ego in a position of having allied adversaries, which is a source of liability for ego.

Insert Figure 1 about here

We further argue, however, that where ego is embedded in "open triads," that is, where there is no direct positive tie between the third individual and the ego (see Figure 1c), ego will experience performance benefits. We argue that this structural position creates a dependence situation that ego can either intentionally or unintentionally exploit to ego's benefit. Finally, we move beyond the triadic level to consider ego's position within the whole network of positive 
and negative ties. We use ego's Bonacich power centrality (Bonacich \& Lloyd, 2004) to test whether underlying structural balance theory tenets, such as whether the individual's direct positive and negative ties are to people who are themselves popular or unpopular, have any discernible difference on ego's performance at work.

This study contributes in a number of ways. We contribute to social network theory (SP Borgatti et al., 2009; Zajonc \& Sherman, 1967) by arguing that positive and negative ties should be studied together. We challenge previous arguments that negative ties are simply liabilities (Labianca \& Brass, 2006) and show that we need more nuanced arguments about the relationship between the social distance (i.e., whether a tie is direct or indirect) and the benefits and liabilities that accrue from that relationship. We contribute to power-dependence exchange theory (e.g., Cook, et al., 1983) by extending arguments beyond whether a positive relationship exists or not as the basis for benefits to accrue, to instead considering that some relationships regularly involve negative flows and exchanges, creating liabilities for some and benefits for others. Finally, we contribute to structural balance theory (e.g., Cartwright \& Harary, 1956; F. Heider, 1958) by considering the possibility that imbalanced triads create differential liabilities and benefits for each member of the triad.

\section{Negative and Positive Ties in Organizations}

Social network research has shown that the right social ties provide distinct benefits. For example, individuals who have relatively weak ties to various social cliques can be more successful in searching for jobs (Granovetter, 1973, 1983). Ties to high-status individuals, crossunit relationships, and dense buy-in networks increase career performance and upward mobility (Bonacich \& Lloyd, 2004; Lin \& Dumin, 1986; Podolny \& Baron, 1997; Seibert, Kraimer, \& 
Liden, 2001). Brokering between unconnected others improves information access and information diversity for individuals in organizations (Ronald Burt, 1992) and being central to an organization's networks of positive social ties increases power (Brass, 1984; Brass \& Burkhardt, 1993). Social networks have also been related to individual creativity (Perry-Smith, 2006), organizational commitment (Morrison, 2002), and turnover (D. Krackhardt \& Porter, 1985, 1986), among other outcomes.

Much of this organizational network research has focused on the structure of ties, with the debates focusing on which type of network structure performs best in a given context (e.g., dense vs. sparse networks; cf., Burt; 1987, 1992, 2001; Coleman 1988). However, there has been less emphasis in understanding the content flows inherent in these network ties (cf, Levin, Walter, \& Murnighan, 2011; Mors, 2010; Rodan \& Galunic, 2004), particularly with regard to affective content flows. This stands in stark contrast with the early social exchange and network researchers, who explicitly considered both the positive and negative affective content of relationships as being critical in explaining individuals' attitudes, behaviors and outcomes (Homans, 1961; Sampson, 1969; Tagiuri, 1958; Thibaut \& Kelley, 1959). Most organizational field research after the 1960s largely concentrated on positive aspects of social networks, specifically on relationships that are positive or neutral, such as friendship or advice-seeking (Cornwell, 2005; G. J. Labianca, 2014). This research rarely examines the potential liabilities in personal social networks (e.g., Gargiulo \& Benassi, 2000), and has largely failed to consider that some relationships convey negative flows and may be damaging to individuals' outcomes. Much of the network research that continued to examine both positive and negative ties together came from a structural balance theory perspective focused mainly on understanding the pressures being brought to bear in triads and larger social structures straining to either maintain or change 
the set of relationships within the structure (e.g., Cartwright \& Harary, 1956; Davis, 1963;

Doreian \& Krackhardt, 2001; Fritz Heider, 1946; Hummon \& Doreian, 2003).

Recent network research has begun to explore the role of negative ties in explaining individual outcomes in organizations in greater depth. In negative-tie relationships, at least one person in a dyad has an enduring negative schema about the other: long-term negative judgments, feelings, and/or behavioral intentions toward another (Casciaro \& Lobo, 2008; G. Labianca \& Brass, 2006). This research suggests that negative ties can reduce performance, keep others from helping, reduce trust, and inspire individuals to hinder another's progress (e.g., Venkataramani \& Dalal, 2007) or harm the individual directly through negative exchanges (Lyons \& Scott, 2012). Individuals with more negative ties are also more likely to have lower social satisfaction in their organization, which leads to lower organizational attachment (Vijaya Venkataramani et al., 2013). Individuals who dislike someone are unlikely to seek advice from the person they dislike, even if that person is highly competent (Casciaro \& Lobo, 2008). Negative relational embeddedness (having negative ties with individuals who are friends with each other) is related to a decrease in cognitive trust received from others (Chua, Ingram, \& Morris, 2008). Individual centrality in a hindrance network, where others hinder an individual from completing their work by withholding valuable resources, results in lower in-role and extrarole performance (Sparrowe et al., 2001). Centrality in a network where individuals have an adversarial or conflictual relationship with others relates to lower satisfaction (Baldwin et al., 1997). All told, evidence is mounting that negative relationship ties can create liabilities for individuals in organizations both because resources are sometimes withheld from them, but also because negative flows are directed toward them. Research further suggests that the impact on outcomes per negative tie appears to be greater than the impact of positive ties (that is, that there 
is a negative asymmetry; cf., Labianca \& Brass, 2006; Venkataramani, et al., 2013).

Missing in this research, however, is a consideration that negative ties can also benefit individuals. To this end, we identify two primary considerations for understanding the potential benefits (and liabilities) of negative ties: social distance and embeddedness. Social distance refers to whether the negative tie is directly experienced by the person or indirectly experienced through another individual or series of individuals (G. Labianca \& Brass, 2006). In the most basic social distance of one, the focal individual is directly connected to someone with whom they have a negative tie (i.e., there is a node distance of one where the edge is negative). When the individuals are socially distant by two links, they are indirectly connected. For example, a focal individual has a friend who is negatively tied with a third person, and the focal individual is then indirectly negatively tied with that third person. Social ledger network theorists (G. Labianca \& Brass, 2006) suggest that all negative ties are liabilities to focal individuals, whether they are direct negative ties or indirect negative ties separated by two links, with the only difference being that as social distance increases, liability to the individual decreases as exposure diminishes. This argument is rooted in an assumption that negative ties are always corrosive and detrimental, and imply that the further the focal individual stays from the negative tie (i.e., the more links separate them) the less detrimental it will be to the focal individual's outcomes. We challenge this view and argue that being the same social distance from a negative tie can sometimes convey liabilities but other times benefits for the focal individual. We argue that the manner in which the negative tie is embedded within triadic structures of mixed positive and negative ties is what is related to the focal actors' outcomes.

Embeddedness refers to the configuration of positive and negative ties in the triad. Specifically, adding a third party to a dyad can create either an "open," pre-transitive triad 
(Doreian \& Krackhardt, 2001) (i.e., a triad where there are two ties and three actors), or "closed," transitive triads (where there are three ties and three actors) (Wasserman \& Faust, 1994: 246) (see Figures 1a-c). These open and closed triads can influence the benefits or liabilities the focal actor receives not only due to the social distance of the negative tie (i.e., whether they are directly involved in the negative tie, or whether they are only indirectly involved through a friend who has a negative tie) but also due to the manner in which the focal actor is embedded in the triad. Specifically, we'll argue that the focal actor can benefit when their friend has a negative tie if that tie is embedded in an open triad (which we will refer to as a PN open triad), but will suffer liabilities if it is embedded in a closed triad where two friends are themselves involved in the negative tie (a structurally imbalanced PNP closed triad). Additionally, we will argue that direct negative ties to two alters who are themselves joined by a positive tie (a structurally balanced NPN closed triad), can be detrimental to ego. Thus, we will argue, and show, that the social distance and manner in which ego is embedded in the positive and negative tie triad will determine how and the degree to which individuals experience potential benefits or liabilities, without regard to issues of structural balance. We begin with arguments linking benefits and liabilities to direct, distance-one ties, and then move to distance-two ties and how they are embedded before exploring ego's position within the whole network.

\section{Social Distance and Embeddedness: Benefits and Liabilities}

\section{Direct Ties}

The simplest mechanism linking negative and positive ties to individual outcomes involves direct ties - ties at a social distance of one - whether they are direct, positive ties on the social assets side of the ledger or direct negative ties on the social liabilities side (K. Klein, 
Harrison, \& Knight, 2005; K. J. Klein, Lim, Saltz, \& Mayer, 2004). Researchers using this tallying approach inherently assume that direct positive ties are always beneficial and direct negative ties are always detrimental. Social resources and social exchange theorists (e.g., Cook et al., 1983; R. Emerson, 1972; R. M. Emerson, 1972; Lin, 2002) suggest that the number of direct positive ties in the egocentric (personal) network, often called tie expansiveness, affects access to critical resources. Individuals with more expansive personal networks can seek information, referrals, and political support from many others (Ronald Burt, 1997; Lin, 1999; Lin \& Dumin, 1986). However, most of this work fails to consider the possibility of recurring negative exchanges - it's not simply that relationships exist or do not, but that there are some flows that can be withheld or corrupted. Individuals with more of these negative network relationships will have heightened liabilities as access to network resources is hindered (e.g., Baldwin et al., 1997; G. Labianca \& Brass, 2006; Lyons \& Scott, 2012; Seibert et al., 2001; V Venkataramani \& Dalal, 2007). Negative ties in the network can funnel harmful effects and further prevent individuals from harnessing productive resources; they can severely limit professional prospects by engendering unfavorable gossip, references, and performance reviews (R Burt \& Knez, 1995, 1996). Individuals who become targets of social undermining might experience diminished social support, reduced work performance, and harmed reputations (Duffy et al., 2002; Grosser, Sterling, Scott, \& Labianca, 2010). Targets might find that their rivals fail to pass along critical work information in a timely manner or might provide intentionally misleading information. All these actions to intentionally undermine or hinder an individual can negatively affect job performance. Thus, from a direct-tie perspective, incoming negative ties in one's network bar access to the performance-enhancing benefits of social network ties and increase possibilities for negative effects. 
H1: Increasing numbers of direct negative ties in an individual's social network will be related negatively to the individual's performance.

\section{Indirect Ties}

Network theory argues that individuals' perceptions, behaviors, and outcomes are affected by others with whom they share no direct connections (RS Burt, 1987; Galaskiewicz \& Burt, 1991; Ibarra \& Andrews, 1993; PV Marsden \& Friedkin, 1993). Thus, individuals might not directly experience negative and positive ties, but those ties will nevertheless influence their outcomes. Indeed, the social distance of an individual from a negative tie (i.e., the number of links between the person and the negative tie on the shortest path or geodesic) may be an important predictor of the social liability that negative ties generate for that individual (G. Labianca \& Brass, 2006; V Venkataramani \& Dalal, 2007).

If negative ties are always detrimental, as originally espoused by social ledger theory, then ego's outcomes will always improve when an intermediary (alter) stands between the ego and the negative tie (G. Labianca \& Brass, 2006). From this perspective, a negative tie separated from the ego at a social distance of two can still damage performance, albeit less than a direct negative tie, and the best advice to give people is to distance themselves as much as possible from these negative ties (e.g., by helping their friend resolve the negative tie or dropping the friendship to increase the social distance from the negative tie).

However, we argue that depending on how they are embedded, negative ties separated by a social distance of two can sometimes be beneficial, improving performance and outcomes for the focal individual. Triads that have both positive and negative ties can either be open triads where ego (person A) only has a direct relationship with person B, but none with person C, and 
where the direct tie is either positive or negative (see Figure 2, open triads 1 and 2). In the closed triad, by contrast, ego has a direct relationship with both persons involved in the triad, and these relationships can also be either positive or negative (see Figure 2, closed triads 3 and 4). We will draw insights from structural balance theory (Cartwright \& Harary, 1956) and a powerdependence social exchange theory perspective (Cook et al., 1983) modified to deal with negative ties to derive whether these triads will create benefits or liabilities for the focal individual.

Insert Figure 2 about here

Open Triads. We argue that benefits can accrue to an ego (person A) who has a positive tie to an alter (person B) that is engaged in a negative tie with a third party (person C) as long as person A is not directly and positively tied to person C (see Figure 2: open triad 1, PN). This allows the triad to remain open. In this situation, we can imagine that persons $\mathrm{B}$ and $\mathrm{C}$ are in a long-term negative relationship. Person B has strong incentive to rely on ego for social support or other resources, such as information and positive gossip, to help offset the liabilities from the detrimental relationship with C. When ego is loyal to the person in need, ego will be rewarded for this loyalty with increased political support, information or increased access to the knowledge, skills, and abilities of the friend in need. Thus, having a friend in need places ego in a relatively powerful position to extract value from the person seeking help (R. Emerson, 1972; R. M. Emerson, 1972). This process can happen either intentionally, with ego demanding greater value in order to associate with someone involved directly in a negative tie, or more likely unintentionally, with the other person volunteering to give up more value to ego, recognizing that 
they are a valuable potential ally and friend. This essentially illustrates the power-dependence view of social exchange (Cook et al., 1983; Emerson, 1962), but where our work extends the theory is in recognizing that the negative tie creates motivation for B to pass along potentially useful resources to ego (Person A), without regard to whether ego demands them (in the original theory, it is simply the lack of alternative partners for positive exchange that motivates exchanging positive resources) (Smith et al., 2014). From this perspective, befriending or maintaining a friendship with an alter in need due to a negative tie allows ego to gain additional opportunities supplied by the alter directly involved in the negative tie. The greater the extent that a particular individual finds themselves in this situation, the more resources should accrue to them, and the better they should perform. Thus:

H2: Increasing numbers of PN open triads in which an individual is embedded (i.e., is tied positively to a person who is, in turn, negatively tied to another person) will be beneficial to that ego's job performance.

An open triad can also exist where individuals are negatively tied to an alter (Person B) who in turn has a positive tie with a third person (C) (see Figure 2: open triad 2, NP). In this case, the focal actor is directly affected by the liabilities of a negative tie, as we argued above, but the addition of a positive tie to a third party can increase liabilities beyond simple direct negative ties (Smith et al., 2014). An enemy with a friend is likely to be emboldened by social support to maintain the negative behavioral intentions toward ego. In addition, enemies with friends can co-opt their positive ties to target liabilities, such as negative gossip and misinformation, indirectly toward ego and potentially reduce the target's political support in the organization (Gargiulo, 1993; Jordan, 1965; Mayes \& Allen, 1977). In those situations where an enemy does not have a friend, the enemy's behavioral latitude is weakened because they have 
less support for their potentially harmful behavior, and fewer opportunities to infuse social poison into the network against ego. From a social exchange perspective, the positive tie from a third party enables the enemy to more freely send liabilities to the focal actor, because the enemy’s friend reduces any potential dependence on the target for exchange (Cook et al., 1983). Thus, we argue that controlling for the number of ego's direct incoming negative ties, having a negative tie to a person with a friend will also prove detrimental to the focal actor's performance. H3: Increasing numbers of NP open triads in which an individual embedded (i.e., is tied negatively to a person who is, in turn, positively tied to another) will be related negatively to that ego's job performance.

Closed Triads. In a closed triad, the focal actor is tied to two alters who themselves are directly tied. One possible closed triad configuration is where the two alters are in a negative tie with each other, but are both in a positive tie with ego (see Figure 2: closed triad 3, PNP). We might expect that egos benefit even more from exchanges when they are friends of both parties that are in a negative relationship because they now have two people dependent on them, rather than only one, and they might be able to play them off of one another in a bid to "auction off" their continued support and affection (e.g., Simmel, 1950).

However, there is now a crucial difference - unlike the case with the open triad, ego now has a positive relationship with both alters. Those positive relationships bring with them norms, obligations, and increased monitoring that were not an issue in the open triad, and which might have different ramifications for ego's outcomes (cf., Krackhardt, 1999). This closed triad is better understood from a balance theory perspective, where we would expect that ego is likely to feel stress when its two friends are in conflict with each other (e.g., Curry \& Emerson, 1970; F. Heider, 1958) draining ego's emotional and cognitive resources needed for focusing on work. 
Facing stress in everyday decisions such as deciding which friend to invite to lunch or which friend to give private information or social support, ego suffers cumulative effects that can negatively impact in-role performance. Structural balance arguments suggest that individuals caught between two individuals or groups in a negative relationship experience liabilities because they want to be loyal to both sides, but cannot publicly support or denounce one side or the other (D. J. Krackhardt, 1999). Ego is "caught in the middle" between two parties that might be monitoring its behavior very closely and, fearing potential backlash, ego might be inhibited in exchanging advice, information, or public support with either side (Oldroyd, Hendron, \& Labianca, 2010). Ironically, even though ego has more direct friends in a closed triad than an open triad, this position decreases the likelihood of productive exchanges with those friends, and interrupts the potential flow of benefits related to those positive ties. Thus, extending balance theory arguments about social strain (Cartwright \& Harary, 1956; F. Heider, 1958; Hummon \& Doreian, 2003) suggests being a broker between two people involved in a negative tie is a net liability for ego.

H4: Increasing numbers of PNP closed triads in which an ego is embedded (i.e., is positively tied to two alters who are themselves negatively tied) will be related to poorer job performance for that ego.

Another closed triad occurs where ego suffers two incoming negative ties from alters that are themselves positively tied (See Figure 2: closed triad 4, NPN). From a balance theory view, this triad is structurally balanced, meaning ego is unlikely to suffer psychological duress from the situation where "the friend of my enemy is my enemy" (Bonacich \& Lloyd, 2004). However, in this closed triad, because those negative ties are embedded within a coalition against ego, potential liabilities focused on ego increase beyond those experienced by merely 
having two direct negative ties, or even those associated with having two direct negative ties, each of whom has an ally. While such a triad is balanced in the Heiderian sense (Fritz Heider, 1946) because ego lacks the cognitive stress associated with the imbalanced PNP triads discussed above, this does not altogether alleviate structural or dependence liabilities inherent in ego's position. Simmel (1955) argued that two parties will coalesce and cohere around a common enemy, even if those parties were once unaffiliated or at odds (e.g., Coser, 1956; Sumner, 1906). The mutual support and cohesion among one's enemies exacerbates the negative will against the other - in this case, ego (e.g., Coser, 1956; Sherwin, 1975; Tajfel, 1982). Indeed, Chua, et al., (2008) found that egos stuck in this type of closed triad (which they referred to as being "negatively relationally embedded") produced a heightened level of distrust for them. This is likely because the two positively tied alters who are projecting negative ties toward ego can work together to coordinate passing skimpy, bad, or even incorrect information to ego and provide corroborating detrimental information about ego to others (such as negative gossip). Being targeted this way, ego experiences the detriments of direct negative ties, in addition to an increased resource deficit from unified enemies, and potent direct and indirect coordinated efforts of focused harm (cf., V Venkataramani \& Dalal, 2007). We would therefore expect that the negative ties of two positively tied alters focused toward ego would increase ego's performance liabilities beyond those experienced for the same number of direct negative ties or direct negative ties from a person with a friend.

H5: Increasing numbers of NPN closed triads (i.e., in which two alters are positively tied to each other and directing negative ties at ego) will be related to poorer job performance for ego. 
Whole Network-Based Beta Centrality. To this point, we have considered a dyadic perspective and a triadic perspective, but we now turn to whether ego's position within the whole network of positive and negative ties can be used to evaluate their potential for beneficial or harmful outcomes. This whole network perspective takes into account all of the individual's positive and negative ties, including indirect ties that extend out to the maximum social distance within a particular network (Bonacich \& Lloyd, 2004). Even a negative tie three (or more) steps removed from the person might still have an impact, either positive or negative, on the person's performance. The main approach to assessing the favorability of a node's position in that type of signed network graph, beta centrality, follows structural balance theory tenets, which are summarized in Table 1 (Cartwright \& Harary, 1956) . These tenets, such as the enemy of my friend is my enemy, can be used not only at the triadic level but also extended beyond a social distance of two. For example, being friends with someone with a negative tie might create additional social liabilities for me — my friend's enemy might withhold information from my friend or provide them with misinformation that then works its way to me, creating a liability. However, if the enemy of my friend is unpopular (my friend's enemy himself has many enemies), my reputation and access to social benefits in the larger network might actually improve.

Insert Table 1 about here

This illustrates how some of the benefits and liabilities accruing to individuals have been theorized to be due to the accumulated status transfer from popular or unpopular individuals through the network when taking a beta centrality perspective to favorable nodal positions. For example, being disliked by an unpopular person has been theorized to increase one's status in a 
group (Bonacich \& Lloyd, 2004). Similarly, having popular friends adds more to one's own popularity, and this social status attainment can produce access to resources in the network and subsequent increases in in-role performance (D. Krackhardt \& Kilduff, 1999; Lin, 1999). This type of status transmission can have a transitive effect - a highly popular individual is theorized to add to the popularity of not only his friends, but indirectly to the status of the friends of his friends, and so on through the entire network (Bonacich \& Lloyd, 2004). Through status transmission based on balance theory tenets, all of the positive and negative ties across all the social distances in the entire network can be considered at once in evaluating the favorability of an individual's position.

To the degree that an individual is positioned well or more centrally within the network according to these balance theory tenets, they are high in beta centrality. High beta centrality indicates which individuals are playing the social game well, and which are not. Those individuals that connect positively with popular people can increase their own popularity in the process, and increase their subsequent inflow of benefits. On the other hand, individuals with negative relationships to popular individuals in their network can impede their in-flow of resources and support from the network. Positive ties to unpopular individuals and negative ties to popular individuals can be detrimental, reducing access to network resources as well as reducing reputational status. An individual higher in beta-centrality within a whole network will ultimately have better in-role performance than an individual lower in beta-centrality because they are indirectly connected to others in the network from which flow potential benefits or liabilities, providing either advantages or disadvantages.

H6: An individual's (beta) centrality in the combined positive and negative tie network will be positively related to the individual's in-role performance. 


\section{Method}

\section{Sample and Setting}

We collected social network data on an entire division of a mid-sized Midwestern U.S. life sciences firm engaged in developing and manufacturing products that test critical aspects of food and animal safety. ${ }^{1}$ The population was all 183 organizational members in this division. Participants were invited into a conference room equipped with notebook computers in small groups of less than 10 individuals, explained their respondent rights regarding voluntary participation and confidentiality, briefed on the purpose of the study, and after obtaining informed consent, they responded to the survey via an online link. In all, 154 organizational members completed the sociometric survey (84\% response rate). Approximately 50\% of respondents were male, and $87 \%$ were white. Tenure within the organization ranged from a few months to more than twenty-one years $(M=4.12$ years, $S D=4.18)$.

Employees reported an average of 0.66 outgoing negative ties $(S D=1.12)$ and 2.12 outgoing positive ties $(S D=2.42)$. These personal networks were relatively small in comparison to previous research on workplace positive and negative ties (e.g., G. Labianca, Brass, \& Gray, 1998). There were likely a number of reasons for this. First, the employees were spread across six buildings on a company campus situated around a central park, with ten to forty-seven respondents in each building $(M=25.6$ employees, $S D=14.4)$, rather than being co-located in one large building which might have provided more opportunity for larger networks to develop. Second, this organization's formal structure was functional (as compared to a matrix structure in G. Labianca et al., 1998), which in combination with numerous but small departments grouped

\footnotetext{
${ }^{1}$ These data were originally published in Zagenczyk, Scott, Gibney, Murrell, \& Thatcher (2010).
} 
by building, meant that there was often little reason for individuals to develop large personal networks that spanned cross-departmentally. Finally, the organization had a relatively high employee turnover rate (approximately 20\% per annum), making it less likely that an enduring, recurring affective relationship had developed, as compared to what might be expected in a more stable organization.

\section{Dependent Variable}

Job Performance. We collected our dependent variable, job performance, from a separately administered supervisor survey. Supervisors rated each subordinate's job performance using a seven-item scale (Cronbach's $\alpha=.88$ ) based on Tsui (1984). Examples of items include: "This employee is performing his/her total job the way I would like it performed," and "I am satisfied with the total contribution this employee has made to the organization" (see Appendix A for all items used in this measure). Not all supervisors completed the separate ratings survey; of those respondents completing the social network survey $(n=154)$, only ninety ( $n=90$ ) had supervisors who rated their job performance (58\% supervisor performance rating response). Because responses in the performance variable could be nonrandom, we analyzed for response bias in the performance measure. We first conducted a logistic regression where the dependent variable was coded 1 if the respondent lacked a performance score, and 0 otherwise. We then regressed the independent and control variables on this dependent variable to check for response bias. The results suggested that individuals in specific buildings and organizational tenure had nonrandom responses for the performance variable. However, no other variables indicated bias, and additional analyses suggested this response bias failed to affect reported results. We conducted additional analyses on possible sample selection bias using the Heckman sample selection model (Heckman, 1979) in STATA 13.1. These analyses showed that potential 
sample selection bias for the dependent variable was not a problem when estimating our models.

The pattern of results using the Heckman model was consistent with the results in the linear regression models reported here. The first author will provide results of these analyses upon request.

\section{Independent Variables}

The independent variables were drawn from the sociometric portion of the survey instrument, which was conducted using the roster method (Peter Marsden, 1990). We asked participants to scan a roster of all 183 people in their organization (grouped first by department and then alphabetically within the departments) to identify relationships with coworkers with whom they interacted regularly. Participants then indicated those from that roster that they considered to be friends, which served as our measure of a positive tie. They also identified those with whom they had negative relationships: "Sometimes people at work make us feel uncomfortable or uneasy, so we try to avoid interacting with them. Do you avoid interacting with this person?" This negative tie measure, which captures both interpersonal judgments and behavioral intentions, is similar to Labianca et al.'s (1998). Using single-item measures for describing these relationships from a roster in a bounded network such as this has proven reliable (Peter Marsden, 1990) and is the standard in whole-network social network research because respondents cannot be expected to answer multi-item measures about each person (in this case, 183 others). One strength of the sociometric approach to data collection is that the network measures described below were based on others' reports rather than self-reports, which increases the validity of the measures and eliminates potential percept-percept bias concerns.

Number of direct negative ties. From these responses, we created variables to capture 
direct and indirect negative ties in an individual's network. We first assessed direct ties by calculating the number of incoming negative ties reported about each individual. Thus, the direct in-negative ties $(\mathrm{N})$ variable represents how many fellow employees named the focal individual as a negative relationship (i.e., in-degree centrality). (See Appendix B for descriptive statistics on the positive and negative tie networks.)

Open triads. The first open triad variable indicated whether an ego was positively tied with an alter who was in turn involved in a negative relationship with a third person (PN). To calculate this variable, we created a dichotomous negative-tie vector (where $1=$ ego has a negative tie; 0 = ego has no negative tie), which was then copied column-wise 153 times to form a square 154 x 154 cell matrix. We then multiplied the positive-tie matrix by this new negativetie matrix, cell-wise. The resulting matrix indicated the dyadic relationships of those who were friends with negatively tied individuals. Summing down the columns of this matrix allowed us to capture the number of positive-negative open triads $(P N)$ in individuals' social networks. We used this same method to also calculate the open triad variable that indicated whether an individual was negatively tied with an alter who was in turn involved in a positive relationship with a third person, or negative-positive open triads (NP). We used in-degree positive and negative ties to calculate the open triad measures. Note that person A, who had an incoming positive or negative tie from $\mathrm{B}$, might also have an outgoing tie to B, making A its own thirdparty tie. We removed these instances from the final open triad measures.

Closed triads. The closed triad variables indicated whether individuals had positive ties to two alters who were involved in a negative tie (PNP) or negative ties to two alters who were involved in a positive tie (NPN). To calculate these variables, we used the "balance counter" algorithm in UCINET 6.3 (S. Borgatti, Everett, \& Freeman, 2002) with our 154 x154 cell 
matrices. This algorithm counts the number of structures where A is positively tied to $\mathrm{B}, \mathrm{B}$ is negatively tied to $\mathrm{C}$, and $\mathrm{C}$ is positively tied to $\mathrm{A}$, or positive-negative-positive triad (PNP), for all ABC triads. This method also calculated the number of structures where A was negatively tied to $\mathrm{B}$, B was positively tied to $\mathrm{C}$, and $\mathrm{C}$ was negatively tied to $\mathrm{A}$, or negative-positivenegative triads (NPN). For this procedure, we used the direct incoming positive and negative tie networks. (See Appendix C for count statistics on the positive and negative tie networks.)

Beta-centrality. To create the beta centrality score, we first combined the positive and negative tie matrices together into a single signed matrix. This new combined matrix was recoded so that the negative relationships were all negatively signed (i.e., -1 ), and the positive relationships were positively signed (i.e., +1) (Bonacich, 2007; Bonacich \& Lloyd, 2004). In the extremely rare case where an individual had both positive and negative ties toward the same person, we counted this is as neither positive nor negative (this occurred eight times out of a possible 23,562 dyads). ${ }^{2}$ We then calculated beta-centrality on the combined positive and negative tie network (Bonacich, 2007; Bonacich \& Lloyd, 2004) using the Bonacich “power” measure (Bonacich, 1987; Bonacich \& Lloyd, 2001) in UCINET 6.5 (S. Borgatti et al., 2002). The beta-centrality coefficient, or alpha, used for this sample was 0.302 , which represents the default $99.5 \%$ of the inverse of the largest eigenvalue. Beta-centrality provides a measure of centrality based on balance theory tenets that incorporates not just the centrality of the focal actor, but the centrality scores of everyone else in the individual's complete social network

\footnotetext{
${ }^{2}$ We recognize that these co-occurrences could also have been coded as positive or negative. Therefore, we computed two additional positive and negative tie-combined matrices, one where we coded these co-occurrences as positive (i.e., 1), and in another as negative (i.e., -1). Beta-centrality was then calculated for each of these two new matrices and was included in two separate OLS regression models in place of the original beta centrality measure reported in Table 4. This analysis showed that the choice of coding method for these eight co-occurrences had no effect on the final model results.
} 
(Bonacich, 1987).

\section{Control Variables}

We controlled for individuals' direct incoming positive ties, or in-positive ties (P) which was the number of times a person was nominated as a positive tie by others in the organization. We controlled for the size of individuals' personal networks by including two network variables that reflected the number of outgoing (out-degree) positive and negative ties for each respondent (individuals who name others as positive or negative ties might be more likely to be selected by others in return). We also controlled for all other types of closed triads the individual might be involved in (i.e., triads with all positive relationships, or positive-positive-positive triads [PPP], and all negative relationships, or negative-negative-negative triads [NNN]).

We further controlled for the average performance of alters to which the individual was tied (alters' performance) to ensure that there weren't any prism/reputational effects on the focal individual from being tied to higher or lower performing alters (e.g., Kilduff \& Krackhardt, 1994). Because the respondents worked in various buildings spread across the company campus, we also controlled for the possibility that people in various buildings might differ significantly in terms of individual performance ratings with building dummies (building 1 to 6 ).

We also sought to control for individual characteristics for the employees surveyed. We included their organizational tenure to control for the possibility that tenure might affect supervisor-rated job performance. Additionally, research has shown that gender (Ibarra, 1992) and ethnicity (Ibarra, 1995) influence people in their adoption of network strategies. Therefore, in models not reported here, we controlled for respondent gender $(1=$ male, $0=$ female $)$ and ethnicity $(1$ = white, 0 = non-white). Inclusion of the gender and ethnicity variables in our 
models did not alter our results, and were not significantly related to performance, thus we did not include them in the models reported here. We retained organizational tenure as a control because it showed marginal significance in some of our models. In addition, to control for the potential that individual differences might attract positive or negative ties from others in the network, we included trait positive affectivity and negative affectivity as part of the survey and included these measures in all models using the Positive and Negative Affectivity Scale, or PANAS (Watson, Clark, \& Tellegen, 1988). The PANAS scale captures individuals' long-term positive and negative affect by asking respondents to describe how often they felt particular emotions or moods over the previous month. Some of the items used included how often they felt distressed, scared, hostile, or irritable indicating negative affect; and how often they felt strong, enthusiastic, proud, and determined indicating positive affect. The scale used was from 1= Never, to 5= All the time. One respondent failed to complete the PANAS scales and was removed from the analyses. All variables are summarized in Table 2.

Insert Table 2 about here

\section{Results}

Supervisors provided job performance ratings for their direct reporting subordinates, so it was important to control for potential supervisor effects in our analyses. It was possible that employee scores correlated within supervisors. Thus, we used a clustering approach to control for this possibility (Williams, 2000). To this end, we used linear regression with robust standard errors clustered around supervisor in STATA 13.1 (Hansen, Mors, \& Løvås, 2005; Moulton, 1986; Rogers, 1994). While this method reduced our final sample size to 84 (because not all 
supervisor data was available), the same pattern of results was found when not clustering around supervisor in the linear regression models (see Appendix D), giving us confidence in our results presented below.

We analyzed the variance inflation factors (VIFs) to ensure that multicollinearity within the regression model presented no problem. Results showed that the VIFs for all variables were within recommended levels (Cohen, Cohen, West, \& Aiken, 2003). Pearson correlations for all variables used in this study can be found in Appendix E. Among our control variables, being involved in an all-negative closed triad (NNN) was significantly related to performance, as was being located in one of the buildings (in results not reported in the table to conserve space); the other control variables were not significant in our regression model (see Table 3 Model 11).

Insert Table 3 about here

\section{Regression Results}

Direct ties. In the regression model (Table 3), individual job performance was not related to the number of incoming positive ties when we controlled for incoming negative ties and triads (Model 11: $\beta=-0.03, t=-.14, n s$ ). However, we found that the number of individuals' incoming negative ties was negatively related to job performance, even while controlling for incoming positive ties and all types of triads, supporting Hypothesis 1 (Model 11: $\beta=-0.46, t=-2.39, p$ $<.05)$. Thus, the more negative ties a person received from others, the lower their job performance. However, the number of positive ties a person received from others was not an important indicator of job performance.

Open triads. Controlling for the number of direct incoming positive and negative ties a 
person had and all types of closed triads in which they were involved, the more times an employee was positively tied to a person involved in a negative tie embedded in an open triad (PN) the better the employee's job performance, supporting Hypothesis 2 (Model 11: $\beta=0.31, \mathrm{t}$ $=2.24, p<.05$ ). The number of times individuals had a negative tie to a person with a friend in an open triad (NP) was not related to job performance, finding no support for Hypothesis 3 (Model 11: $\beta=0.26, \mathrm{t}=1.50, n s$ ). This means that having a friend with an enemy was related to better job performance, while having an enemy with a friend was unrelated to performance.

Closed triads. Controlling for the number of incoming positive and negative ties, open triads, and the all-positive and all-negative closed triads, we found that employees who had two friends with a negative tie between them (PNP) did have a marginally significant negative relationship to job performance, finding support for Hypothesis 4 (Model 11: $\beta=-0.19, t=-$ 1.99, $p=.056$ ). Finally, we found a significant detrimental relationship with job performance for closed triads where an individual had negative ties with two alters who had a positive tie between them (NPN) (Model 11: $\beta=-0.22, t=-2.03, p<.05$ ), supporting Hypothesis 5. Thus, individuals who had two enemies who were friends with each other had lower job performance; and having two friends in conflict was also negatively related to job performance. This contrasts with results from the open triad (PN) which showed that indirect negative ties were beneficial and related to better job performance. Indirect negative ties are, therefore, sometimes beneficial and sometimes liabilities to ego's performance, while direct negative ties are detrimental.

Whole Network. A person's beta-centrality score from the combined positive and negative tie network was not related to individual performance in the full model when controlling for incoming direct ties and open and closed triads. Therefore, our results did not support Hypothesis 6 (Model 11: $\beta=0.20, t=0.89, n s$ ). However, as can be seen in Appendix 
E, beta-centrality was significantly correlated to in-role performance $(r=.33, \mathrm{p}<.01)$, but this did not translate to significance in the full model.

\section{Discussion}

Most social network research in organizations has focused exclusively on the structure of ties, without regard to the content or flows which make their way through those ties. While this has been a useful approach to understanding workplace social networks, it is important to recognize that the lack of specificity in content flows can be masking the true nature of the value of those interpersonal networks in determining individuals' outcomes in organizations (cf, Mors, 2010; Rodan \& Galunic, 2004). Indeed, organizational network scholars are increasingly recognizing that simply examining structure without understanding content flows, or the unique roles that actors might be playing in the network, obscures what is truly happening within the network (Mayes \& Allen, 1977) . In particular, ignoring the reality that every organization has associative and dissociative forces (Simmel, 1955), and that these are instantiated in the positive and negative ties between organizational members leaves us unable to appreciate the complexities of organizational life. Negative ties are a normal and important part of group and organizational life, and our network research needs to treat them as such by explicitly examining them in combination with positive ties. While there have been increasing numbers of social network articles that examine negative ties, few have examined negative ties in consort with the constellation of relationships in the broader social network. Our approach clearly demonstrates that looking beyond the negative tie dyad uncovers the potential benefits of negative ties in particular structures (G. Labianca \& Brass, 2006). While it is true that our results show that negative ties can, indeed, be detrimental to outcomes when individuals are involved in them 
directly, this is only part of the story. Our results also illustrate that negative ties at a social distance of two from the focal actor can be beneficial depending on whether the focal actor is in an open or closed triad. Thus, future research should include both positive and negative ties, and look beyond the dyad, to provide a more valid and properly specified theoretical representation of the social world.

\section{Summary and Theoretical Implication of Findings}

While this study does not negate previous research or theorizing around negative ties, it does empirically corroborate, expand, and challenge some propositions from previous theorizing (cf, G. Labianca \& Brass, 2006). Specifically, we find support that direct negative ties negatively relate to individual job performance even when considered in combination with positive ties. Our results do not suggest that the number of direct negative ties explains job performance in addition to direct positive ties, but rather we find potential evidence for the negative asymmetry effect (Taylor, 1991) which argues that negative ties are more important in explaining individuals' outcomes than are positive ties because they are rarer and more informative.

We caution that these results do not suggest that positive ties are unimportant for understanding organizational outcomes. Indeed, the most consistent relationships have been found between individual outcomes and people's structural position in positive-tie networks (i.e., structural holes as related to performance, e.g., Burt, 1992). However, more than $90 \%$ of published organizational network research ignores negative ties and the effects of negative content flowing through networks (Cornwell, 2005). For network research to be so heavily biased toward the positive side of the social life in organizations undermines its ability to reflect what actually occurs in the workplace. In failing to account for negative ties in the analysis of 
most social network data, researchers may be overlooking some of the most critical relationships that explain job performance outcomes, particularly where a great deal of underlying competition occurs between individuals for resources and outcomes (cf., Siegel, 2007).

We explored the assumption that negative ties are always detrimental to performance. Specifically, our findings dispute those assumptions when an actor is positively tied to a person with a negative tie in an open triad (PN). Consistent with a power dependence view of social exchange theory (Cook et al., 1983), we find that negative ties may accrue benefits to those who are not directly involved at a social distance of one, but rather at a social distance of two from the negative tie. When person $B$ has a negative tie from person $C$, actor $A$ then has the power to leverage exchanges with $\mathrm{B}$, who is otherwise relegated to unproductive or even detrimental exchanges with C (in the PN open triad). Thus, negative ties may benefit those who are wellpositioned to intentionally or unintentionally capitalize on the opportunities made available by the dependent alters.

We did not find evidence that individuals embedded in open triads where ego has a negative tie to a person with a positive relationship to a third party (NP open triads) related to decreased job performance. This suggests that the liabilities associated with direct negative ties are not significantly increased when that alter has an unaffiliated friend. This might indicate the liabilities flowing from alter toward ego may not depend on the alters' level of social support. However, we did find that most individuals who had outgoing negative ties did also have incoming friendship ties. Indeed, 83\% of individuals who had at least one outgoing negative tie also had at least one incoming positive tie, and 100\% had at least one incoming or outgoing positive tie. Thus, variance with respect to direct negative ties' having unaffiliated third party positive ties was low, possibly resulting in the lack of a significant effect in our models. We 
speculate that individuals with friends were possibly more likely to nominate others as negative ties because they had established social support in the organization. Admittedly, it was not possible to directly test this notion in this study. However, future inquiry should examine whether such structural antecedents as positive tie embeddedness relate to when negative ties develop in an organization.

We did find support that egos embedded in a closed triad, where egos' two negative ties were themselves friends of each other (NPN closed triads), had lower job performance, even after controlling for ego's number of direct negative ties. This suggests that two friends can combine forces against ego to produce liabilities beyond those experienced when ego has an enemy with an unaffiliated friend in an open triad. The addition of the second negative tie closing the triad is vital in understanding the social liabilities associated with negative ties. It also highlights the greater potential liabilities associated with a coordinated, mutually supported coalition of enemies (Maoz, Kuperman, Terris, \& Talmud, 2006). This brings to the forefront the importance of considering the embeddedness of ties within ego's local structure (Chua et al., 2008). Only considering ego's direct ties would ignore the importance of these structural features, providing only partial explanations of factors influencing job performance.

Our findings supported arguments predicting that individuals positively tied to two alters involved in a negative tie (PNP) would be seen as potentially disloyal or unreliable and, thus, be excluded from gaining instrumental resources, as evidenced by having worse performance. It might be the case that the expressive resources, such as emotional support or affection from direct positive ties, are not enough to mitigate the potentially negative ramifications for performance of not being trusted with instrumental resources such as sensitive information or negative gossip. Additionally, the potential emotional and cognitive stress from being embedded 
in an imbalanced triad could interfere with the focal persons' attention to work-related tasks due to increased emotional strain. Individuals who are "caught in the middle" face the relational conundrum of potentially choosing one friend and losing the other in the process, creating an enemy. Loyalty and continued positive resource flows from both parties to ego is unlikely as one alter might fear their resources might be shared with the enemy. Thus, these positive and negative tie structures can impart difficult situations on ego: despite having two friends, ego is unable to capitalize on those positive ties, and experiences worse performance.

Finally, we tested a whole network view of positive and negative ties on in-role performance through the use of beta-centrality in the combined positive and negative tie network (Bonacich, 2007; Bonacich \& Lloyd, 2004). This perspective takes into account all of the individual's positive and negative ties, including indirect ties that extend out to the maximum social distance within the network. It assumes that status is transmitted through the network by way of balance theory tenets. Our results, however, did not support this integrated view of positive and negative workplace ties. This might have been due to either issues of sample and setting and/or issues with the underlying measure itself. The sample was collected from an organization where the individuals were in six separate buildings in a campus setting. This might have produced a network that was lower in density and higher in social distance than one might expect in an organization where everyone is co-located. This might have reduced the amount of variance in individuals' status ratings and status transmission in this network because there is less opportunity for a person to be selected as a positive or negative tie. Another possibility is the measure is not capturing the effects of social distance properly. Beta-centrality is designed to rely on balance theory, which is inherently based around triads, but then attempts to extend that logic beyond the social distance of two, which might be problematic. Future researchers should 
determine whether our results are generalizable to other settings, and whether this measure works in other settings.

Our study has implications for organizational psychology, which has predominantly studied individual differences in relation to outcomes. We suggest broader and critical implications for studying individual organizational outcomes using an approach that considers people within their socio-structural contexts. Researchers oriented to individual-differences might examine our direct positive and negative tie results and conclude that individual differences in interpersonal desirability were driving the poorer job performance. These researchers might argue that interpersonal desirability drives the number of incoming negative ties, that we could simplify studies by skipping network data collection and instead directly examine the relationships between job performance, interpersonal desirability, and other personality characteristics. However, neither positive nor negative affectivity was related to individuals' network popularity (incoming direct positive or negative ties). Even controlling for demographic individual differences (such as organizational tenure) and for the number of direct positive and negative ties, having a friend who has a negative tie relates to better job performance, and having two enemies who are friends relates to worse job performance. Individual-difference approaches would overlook these triadic phenomena, which have the added advantage of not being open to single-source bias because they rely on the perceptions of everyone involved in the network. Only by taking a more structural viewpoint at a level of analysis higher than the individual or the dyad will we be able to more effectively capture such effects. 


\section{Practical Implications of Findings}

This research indicates that it is wise to avoid being directly involved in long-term negative relationships. The presence and source of negative relationships may be difficult to discern at times, but individuals would do well to actively seek advice for resolving or eliminating conflicts and minimizing direct negative ties in their networks. Nevertheless, they should not distance themselves entirely from those in enduring relationship conflict; they may derive some benefits from being tied to others who are engaged in ongoing conflicts. Thus, the most successful individuals must delicately balance negative relationships; surreptitiously capitalizing on conflict without being drawn into it directly. This can backfire, however, when the negative tie is between two friends. Additionally, conflicts with actors aligned in coalitions against you can be detrimental beyond the liabilities associated with direct negative ties; thus, while avoiding direct negative ties is advisable, avoiding enemies that are aligned is paramount to minimizing the liabilities of direct negative ties.

An important consideration with practical implications in organizations is whether a person should avoid or possibly help a friend who develops a negative tie. On one hand an individual might wish to avoid conflict by distancing herself even further from the negative tie, while on the other hand a friend in need is a friend indeed — that is, individuals might be inclined to support a friend who is embroiled in a negative tie. Our results suggest that friends with conflict should not be avoided or "defriended." Rather, there are benefits to those positive ties in conflict, and such knowledge might encourage individuals to remain steadfast in their positive relationships, even when faced with the prospect of indirect negative relationships at work. 


\section{Limitations and Future Research}

To determine the generalizability of our findings, future research should study the effects of negative ties in other organizational settings. We collected our sample from an organization in which workplaces were scattered throughout six buildings surrounding a central park. A sample collected from individuals working in a single building might have yielded different data. The organization was also set up in a functional organizational structure, which made for small personal networks due to the reduced need to connect to far-flung others. This might have magnified the importance of what few network ties the individuals had for performance, as compared to organizations where the personal networks are larger.

The cross-sectional nature of our data and analysis prevents causal surety in terms of our independent and outcome variables. However, it is unlikely that the open and closed triad results could have been driven by reverse causality; nonetheless, we cannot completely rule out the potential that previous work performance influences network evolution and subsequent performance outcomes.

Future research might investigate triad structures such as ours to understand how these particular structures develop dynamically and whether their sequence or genesis relates to potential benefits and liabilities for the focal actor. Based on Simmel's (1950) arguments, under some circumstances two people in conflict (a negative dyad) might draw in a third person to settle or mediate the dispute. In such cases the focal person is given greater license to mediate and an opportunity to extract personal benefits from the conflict (i.e., tertius gaudens). In other instances, the conflict might arise in an already closed triad, where three individuals are tied to one another, and two develop a negative tie. In this instance, the focal person might be more likely to experience detrimental effects and less likely to take advantage of the conflict (F. 
Heider, 1958; Hummon \& Doreian, 2003). The third possibility is that the individual instigates conflict among two others to then capitalize on the conflict (i.e., divide et impera; Simmel, 1950). A dynamic view could also indicate how individuals approach negative ties that lie one and two steps away. For example, do some individuals actively pursue enduring conflict ties to capitalize on them? Motivated by individual differences, some might willingly put themselves into open triad positions to gain beneficial opportunities (e.g., those high in Machiavellianism or political opportunism). Other promising research in the personality-network position connection has been looking at the role of self-monitoring and individuals' likelihood to fill positions as brokers between two unconnected alters over time (Sasovova, Mehra, Borgatti, \& Schippers, 2010), and a similar approach might be fruitful with regard to negative tie triads.

\section{Conclusion}

Our study does not negate prior social capital or social network research, but it does show that understanding negative ties is important for predicting individual performance in the workplace, and that studying positive and negative ties together is particularly fruitful. We show that conditions that are detrimental for those directly involved in negative relationships can be detrimental or beneficial for those indirectly tied to those in conflict, emphasizing the importance of both social distance and the embeddedness of the focal actor in positive and negative tie triads. Only by moving beyond the social capital metaphor, which overemphasizes the positive benefits of social networks, can we understand the subtle complexities associated with individuals' ledgers of social benefits and liabilities derived from the positive and negative ties in their workplace networks. 


\section{References}

Baldwin, T., Bedell, M., \& Johnson, J. (1997). The social fabric of a team-based MBA program: network effects on student satisfaction and performance. Academy of Management Journal, 40(6), 1369-1397.

Bonacich, P. (1987). Power and centrality: a family of measures. American Journal of Sociology, 92(5), 1170-1182.

Bonacich, P. (2007). Some unique properties of eigenvector centrality. Social Networks, 29(4), $555-564$.

Bonacich, P., \& Lloyd, P. (2001). Eigenvector-like measures of centrality for asymmetric relations. Social Networks, 23(3), 191-201.

Bonacich, P., \& Lloyd, P. (2004). Calculating status with negative relations. Social Networks, 26(4), 331-338.

Borgatti, S., Everett, M., \& Freeman, L. (2002). Ucinet for Windows: software for social network analysis version 3.615. Harvard, MA: Analytic Technologies.

Borgatti, S., \& Foster, P. (2003). The network paradigm in organizational research: a review and typology. Journal of Management, 29(6), 991-1013.

Borgatti, S., Mehra, A., Brass, D., \& Labianca, G. (2009). Network analysis in the social sciences. Science, 323(5916), 892. 
Brass, D. (1984). Being in the right place: a structural analysis of individual influence in an organization. Administrative Science Quarterly, 29(4), 518-539.

Brass, D., \& Burkhardt, M. (1993). Potential power and power use: an investigation of structure and behavior. Academy of Management Journal, 36(3), 441-470.

Brass, D., Galaskiewicz, J., Greve, H., \& Tsai, W. (2004). Taking stock of networks and organizations: A multilevel perspective. Academy of Management Journal, 47(6), 795817.

Brief, A. P., Umphress, E. E., Dietz, J., Butz, R. M., Burrows, J., \& Scholten, L. (2005). Community matters: realistic group conflict theory and the impact of diversity. Academy of Management Journal, 48(5), 830-844.

Burt, R. (1987). Social contagion and innovation: Cohesion versus structural equivalence. American Journal of Sociology, 92(6), 1287.

Burt, R. (1992). Structural holes: The social structure of competition. Cambridge, Mass.: Harvard University Press.

Burt, R. (1997). The contingent value of social capital. Administrative Science Quarterly, 42(2), 339-365.

Burt, R., \& Knez, M. (1995). Kinds of third-party effects on trust. Rationality and Society, 7(3), 255. 
Burt, R., \& Knez, M. (1996). Trust and third-party gossip. Trust in organizations: Frontiers of theory and research, 68, 89.

Cartwright, D., \& Harary, F. (1956). Structural balance: a generalization of Heider's theory. Psychological Review, 63(5), 277-293.

Casciaro, T., \& Lobo, M. (2008). When competence is irrelevant: the role of interpersonal affect in task-related ties. Administrative Science Quarterly, 53(4), 655-684.

Chua, R., Ingram, P., \& Morris, M. (2008). From the head and the heart: Locating cognition-and affect-based trust in managers' professional networks. The Academy of Management Journal, 51(3), 436-452.

Cohen, J., Cohen, P., West, S., \& Aiken, L. (2003). Applied multiple regression/correlation analysis for the behavioral sciences (3rd ed.). Mahwah, NJ: Earlbaum.

Cook, K., Emerson, R., Gillmore, \& Yamagishi. (1983). The distribution of power in exchange networks: theory and experimental results. The American Journal of Sociology, 89(2), 275-305.

Cornwell, B. (2005). The Positive Value of Negative Ties. Unpublished Manuscript, University of Chicago.

Coser, L. A. (1956). The functions of social conflict. Glencoe, Ill.,: Free Press.

Curry, T. J., \& Emerson, R. M. (1970). Balance Theory: a theory of interpersonal attraction? Sociometry, 33(2), 216-238. 
Davis, J. A. (1963). Structural balance, mechanical solidarity, and interpersonal relations. American Journal of Sociology, 444-462.

Doreian, P., \& Krackhardt, D. (2001). Pre-transitive balance mechanisms for signed networks. Journal of Mathematical Sociology, 25(1), 43-67.

Duffy, M., Ganster, D., \& Pagon, M. (2002). Social undermining in the workplace. Academy of Management Journal, 45(2), 331-351.

Ellwardt, L., Labianca, G. J., \& Wittek, R. (2011). Who are the objects of positive and negative gossip at work?: a social network perspective on workplace gossip. Social Networks.

Emerson, R. (1972). Exchange theory, part I: a psychological basis for social exchange. Sociological theories in progress, 2, 38-87.

Emerson, R. M. (1962). Power-Dependence Relations. American Sociological Review, 27(1), 3141.

Emerson, R. M. (1972). Exchange theory, part II: exchange relations and networks. Sociological theories in progress, 2, 58-87.

Galaskiewicz, J., \& Burt, R. S. (1991). Interorganization contagion in corporate philanthropy. Administrative Science Quarterly, 36, 88-105.

Gargiulo, M. (1993). Two-step leverage: managing constraint in organizational politics. Administrative Science Quarterly, 38(1), 1-19. 
Gargiulo, M., \& Benassi, M. (2000). Trapped in your own net? network cohesion, structural holes, and the adaptations of social capital. Organization Science, 11(2), 183-196.

Granovetter, M. (1973). The strength of weak ties. American Journal of Sociology, 78(6), 13601380.

Granovetter, M. (1983). The strength of weak ties: A network theory revisited. Sociological theory, 1, 201-233.

Grosser, T. J., Sterling, C. M., Scott, K. D., \& Labianca, G. J. (2010). Social netowrks, groups, and social exclusion. In L. Neider \& C. Schriesheim (Eds.), The" dark" side of management (Vol. 8, pp. 143).

Hansen, M. T., Mors, M. L., \& Løvås, B. (2005). Knowledge sharing in organizations: multiple networks, multiple phases. The Academy of Management Journal, 48(5), 776-793.

Heckman, J. (1979). Sample selection bias as a specification error. Econometrica: Journal of the econometric society, 47(1), 153-161.

Heider, F. (1946). Attitudes and cognitive organization. The Journal of psychology, 21(1), 107112.

Heider, F. (1958). The psychology of interpersonal relations. New York: Wiley.

Hirsch, B. J., \& Rapkin, B. D. (1986). Social networks and adult social identities: Profiles and correlates of support and rejection. American journal of community psychology, 14(4), 395-412. 
Homans, G. C. (1961). Social behavior: Its elementary forms. New York: Harcourt, Brace, \& World.

Hummon, N. P., \& Doreian, P. (2003). Some dynamics of social balance processes: bringing Heider back into balance theory. Social Networks, 25(1), 17-49.

Ibarra, H. (1992). Homophily and differential returns: sex differences in network structure and access in an advertising firm. Administrative Science Quarterly, 37(3), 422-447.

Ibarra, H. (1995). Race, opportunity, and diversity of social circles in managerial networks. Academy of Management Journal, 38(3), 673-703.

Ibarra, H., \& Andrews, S. B. (1993). Power, social influence, and sense making: Effects of network centrality and proximity on employee perceptions. Administrative Science Quarterly (Vol. 38, pp. 277-303).

Jordan, N. (1965). The "asymmetry" of "liking" and "disliking": a phenomenon meriting further reflection and research. Public Opinion Quarterly, 315-322.

Klein, K., Harrison, D., \& Knight, A. (2005, August). Time and ties in teams: development and determinants of intra-group network structures. Paper presented at the Academy of Management Annual Meeting, Honolulu, HI.

Klein, K. J., Lim, B. C., Saltz, J. L., \& Mayer, D. M. (2004). How do they get there? An examination of the antecedents of centrality in team networks. Academy of Management Journal, 47(6), 952-963. 
Krackhardt, D., \& Kilduff, M. (1999). Whether close or far: social distance effects on perceived balance in friendship networks. Journal of Personality \& Social Psychology (Vol. 76, pp. 770-782).

Krackhardt, D., \& Porter, L. (1985). When friends leave: a structural analysis of the relationship between turnover and stayers' attitudes. Administrative Science Quarterly, 30(2), 242261.

Krackhardt, D., \& Porter, L. (1986). The snowball effect: turnover embedded in communication networks. Journal of applied psychology, 71(1), 50-55.

Krackhardt, D. J. (1999). The ties that torture: Simmelian tie analysis in organization. Research in the Sociology of Organizations, 16, 183-210.

Labianca, G., \& Brass, D. (2006). Exploring the social ledger: negative relationships and negative asymmetry in social networks in organizations. Academy of Management Review, 31(3), 596-614.

Labianca, G., Brass, D., \& Gray, B. (1998). Social networks and perceptions of intergroup conflict: the role of negative relationships and third parties. The Academy of Management Journal, 41(1), 55-67.

Labianca, G. J. (2014). Negative ties in organizational networks. Research in the Sociology of Organizations, 40, 239-259. 
Levin, D. Z., Walter, J., \& Murnighan, J. K. (2011). Dormant ties: the value of reconnecting. Organization Science, 22(4), 923-939.

Lin, N. (1999). Social networks and status attainment. Annual Reviews in Sociology, 25(1), 467487.

Lin, N. (2002). Social capital: a theory of social structure and action. New York: Cambridge Univ Press.

Lin, N., \& Dumin, M. (1986). Access to occupations through social ties. Social Networks, 8(4), $365-385$.

Lyons, B., \& Scott, B. (2012). Integrating social exchange and affective explanations for the receipt of help and harm: a social network approach. Organizational Behavior \& Human Decision Processes, 117(1), 66-79.

Maoz, Z., Kuperman, R. D., Terris, L., \& Talmud, I. (2006). Structural equivalence and international conflict: a social networks analysis. Journal of Conflict Resolution, 50(5), 664-689.

Marsden, P. (1990). Network data and measurement. Annual Review of Sociology, 16, 435-463.

Marsden, P., \& Friedkin, N. (1993). Network studies of social influence. Sociological Methods \& Research, 22(1), 127.

Mayes, B. T., \& Allen, R. W. (1977). Toward a definition of organizational politics. Academy of Management Review, 2(4), 672-678. 
Morrison, E. (2002). Newcomers' relationships: the role of social network ties during socialization. Academy of Management Journal, 45(6), 1149-1160.

Mors, M. L. (2010). Innovation in a global consulting firm: when the problem is too much diversity. Strategic management journal, 31(8), 841-872.

Moulton, B. R. (1986). Random group effects and the precision of regression estimates. Journal of econometrics, 32(3), 385-397.

Newcomb, T. M. (1968). Interpersonal balance. In R. P. Abelson \& et al. (Eds.), Theories of cognitive consistency: a sourcebook (pp. 28-51). Rand-McNally: Chicago.

Oldroyd, J., Hendron, M., \& Labianca, G. (2010). Peacemaking at a price: the performance effects of brokering negative affect relationships. Unpublished manuscript.

Pagel, M. D., Erdly, W. W., \& Becker, J. (1987). Social networks: we get by with (and in spite of) a little help from our friends. Journal of Personality and Social Psychology, 53(4), 793.

Perry-Smith, J. (2006). Social yet creative: the role of social relationships in facilitating individual creativity. The Academy of Management Journal, 49(1), 85-101.

Podolny, J., \& Baron, J. (1997). Resources and relationships: social networks and mobility in the workplace. American Sociological Review, 62(5), 673-693. 
Rodan, S., \& Galunic, C. (2004). More than network structure: how knowledge heterogeneity influences managerial performance and innovativeness. Strategic management journal, 25(6), 541-562.

Rogers, W. (1994). Regression standard errors in clustered samples. Stata technical bulletin, $3(13)$.

Rook, K. (1984). The negative side of social interaction: impact on psychological well-being. Journal of Personality and Social Psychology, 46(5), 1097-1108.

Sampson, S. (1969). Crisis in a Cloister. (Doctoral Dissertation), Cornell University.

Sasovova, Z., Mehra, A., Borgatti, S. P., \& Schippers, M. C. (2010). Network churn: the effects of self-monitoring personality on brokerage dynamics. Administrative Science Quarterly, 55(4), 639-670.

Seibert, S., Kraimer, M., \& Liden, R. (2001). A social capital theory of career success. Academy of Management Journal, 44(2), 219-237.

Sherwin, R. G. (1975). Structural balance and thes sociomatrix: finding triadic valence structures in signed adjacency matrices. Human Relations, 28(2), 175-189.

Siegel, J. (2007). Contingent political capital and international alliances: evidence from South Korea. Administrative Science Quarterly, 52(4), 621-666.

Simmel, G. (1950). The sociology of Georg Simmel (K. Wolff, Trans.). Glencoe, IL: The Free Press. 
Simmel, G. (1955). Conflict and the web of group affiliations (K. Wolff, Trans.). New York: The Free Press.

Smith, J. M., Halgin, D. S., Kidwell-Lopez, V., Labianca, G., Brass, D. J., \& Borgatti, S. P. (2014). Power in politically charged networks. Social Networks, 36, 162-176.

Sparrowe, R., Liden, R., Wayne, S., \& Kraimer, M. (2001). Social networks and the performance of individuals and groups. Academy of Management Journal, 44(2), 316-325.

Sumner, W. G. (1906). Folkways. Boston: Ginn \& Co.

Tagiuri, R. (1958). Social preference and its perception. In R. Tagiuri \& L. Petrullo (Eds.), Person perception and interpersonal behavior (pp. 316-336). London: Stanford University Press.

Tajfel, H. (1982). Social identity and intergroup relations. Cambridge: Cambridge University Press.

Thibaut, J. W., \& Kelley, H. H. (1959). The Social Psychology of Groups: John Wiley.

Tsui, A. (1984). A role set analysis of managerial reputation. Organizational Behavior \& Human Performance, 34(1), 64-96.

Venkataramani, V., \& Dalal, R. (2007). Who helps and harms whom? relational antecedents of interpersonal helping and harming in organizations. Journal of applied psychology, 92(4), 952-966. 
Venkataramani, V., Labianca, G. J., \& Grosser, T. (2013). Positive and negative workplace relationships, social satisfaction, and organizational attachment. Journal of applied psychology, 98(6), 1028.

Wasserman, S., \& Faust, K. (1994). Social network analysis: methods and applications: Cambridge University Press.

Watson, D., Clark, L., \& Tellegen, A. (1988). Development and validation of brief measures of positive and negative affect: The PANAS scales. Journal of Personality and Social Psychology, 54(6), 1063-1070.

Williams, R. L. (2000). A note on robust variance estimation for cluster-correlated data. Biometrics, 56(2), 645-646.

Zagenczyk, T. J., Scott, K. D., Gibney, R., Murrell, A. J., \& Thatcher, J. B. (2010). Social influence and perceived organizational support: a social networks analysis. Organizational Behavior and Human Decision Processes, 111(2), 127-138.

Zajonc, R. B. (1960). The concepts of balance, congruity, and dissonance. Public Opinion Quarterly, 24(2), 280-296.

Zajonc, R. B., \& Sherman, S. J. (1967). Structural balance and the induction of relations. Journal of Personality, 35(4), 635-650. 
Table 1

Balance theory tenets, centrality, and anticipated benefits/ liabilities

\begin{tabular}{|c|c|c|}
\hline Balance theory tenet & $\begin{array}{l}\text { Selective affiliation } \\
\text { implication }\end{array}$ & $\begin{array}{l}\text { Anticipated } \\
\text { outcome }\end{array}$ \\
\hline $\begin{array}{l}\text { A. Friends of } \\
\text { friends are } \\
\text { friends }\end{array}$ & $\begin{array}{l}\text { A direct positive tie to a } \\
\text { popular individual (one with } \\
\text { many positive ties) increases } \\
\text { one's status }\end{array}$ & $\begin{array}{l}\text { Creates social } \\
\text { benefits }\end{array}$ \\
\hline $\begin{array}{l}\text { B. Friends of } \\
\text { enemies are } \\
\text { enemies }\end{array}$ & $\begin{array}{l}\text { A direct positive tie to an } \\
\text { unpopular individual decreases } \\
\text { one's status }\end{array}$ & $\begin{array}{l}\text { Creates social } \\
\text { liabilities }\end{array}$ \\
\hline $\begin{array}{l}\text { C. Enemies of } \\
\text { friends are } \\
\text { enemies }\end{array}$ & $\begin{array}{l}\text { A direct negative tie to a } \\
\text { popular individual decreases } \\
\text { one's status }\end{array}$ & $\begin{array}{l}\text { Creates social } \\
\text { liabilities }\end{array}$ \\
\hline $\begin{array}{l}\text { D. Enemies of } \\
\text { enemies are } \\
\text { friends }\end{array}$ & $\begin{array}{l}\text { A direct negative tie to an } \\
\text { unpopular individual increases } \\
\text { one's status }\end{array}$ & $\begin{array}{l}\text { Creates social } \\
\text { benefits }\end{array}$ \\
\hline
\end{tabular}

Adapted from: Bonacich and Lloyd, 2004 
Table 2

Name, Mean, Standard deviation, And Description of Variables Used For Quantitative Analysis

\begin{tabular}{|c|c|c|c|c|}
\hline & Variable Name & M & SD & Variable Description \\
\hline 1 & Job Performance & 4.00 & 0.70 & Supervisor-rated subordinate job performance. \\
\hline 2 & Building 1 & 0.21 & 0.41 & A dummy variable for individuals working in building 1 \\
\hline 3 & Building 2 & 0.21 & 0.41 & A dummy variable for individuals working in building 2 \\
\hline 4 & Building 3 & 0.08 & 0.27 & A dummy variable for individuals working in building 3 \\
\hline 5 & Building 4 & 0.12 & 0.33 & A dummy variable for individuals working in building 4 \\
\hline 6 & Building 5 & 0.31 & 0.46 & A dummy variable for individuals working in building 5 \\
\hline 7 & Building 6 & 0.06 & 0.25 & A dummy variable for individuals working in building 6 \\
\hline 8 & Tenure & 4.12 & 4.18 & $\begin{array}{l}\text { Length of time in years respondents have been employed at the } \\
\text { organization }\end{array}$ \\
\hline 9 & Positive Affectivity & 3.64 & 0.51 & Self-report measure of trait positive affectivity of each respondent. \\
\hline 10 & Negative Affectivity & 2.47 & 0.64 & Self-report measure of trait negative affectivity of each respondent. \\
\hline 11 & Alters' Performance & 2.54 & 2.08 & Average job performance across each individual's direct positive ties. \\
\hline 12 & Positive Closed Triads & 1.25 & 2.59 & $\begin{array}{l}\text { Number of triads where the focal actor has a positive relationship to } \\
\text { two people who have a positive relationship with each other (PPP). }\end{array}$ \\
\hline 13 & Negative Closed Triads & 0.06 & 0.30 & $\begin{array}{l}\text { Number of triads where the focal actor has a negative relationship to } \\
\text { two people who have a negative relationship with each other (NNN). }\end{array}$ \\
\hline 14 & Positive Out Ties & 2.12 & 2.42 & Number of people for whom the respondent reported a positive tie. \\
\hline 15 & Negative Out Ties & 0.66 & 1.12 & Number of people for whom the respondent reported a negative tie. \\
\hline 16 & Positive In Ties & 2.12 & 1.77 & $\begin{array}{l}\text { Number of people who report a positive relationship with the } \\
\text { respondent. }\end{array}$ \\
\hline 17 & Negative In Ties & 0.66 & 0.99 & $\begin{array}{l}\text { Number of people who report a negative relationship with the } \\
\text { respondent. }\end{array}$ \\
\hline 18 & $\begin{array}{l}\text { My enemy has a } \\
\text { friend NP }\end{array}$ & 1.64 & 2.95 & $\begin{array}{l}\text { Number of triads where the focal person has a negative relationship } \\
\text { with someone involved in a positive relationship (NP). }\end{array}$ \\
\hline 19 & $\begin{array}{l}\text { My friend has an } \\
\text { enemy PN }\end{array}$ & 1.02 & 1.49 & $\begin{array}{l}\text { Number of triads where the focal person has a positive relationship } \\
\text { with someone involved in a negative relationship (PN). }\end{array}$ \\
\hline 20 & $\begin{array}{l}\text { Friend of my enemy } \\
\text { is my friend PNP }\end{array}$ & 0.13 & 0.42 & $\begin{array}{l}\text { Number of triads where the focal actor has a positive relationship to } \\
\text { two people who have a negative relationship with each other (PNP). }\end{array}$ \\
\hline 21 & $\begin{array}{l}\text { Enemy of my friend } \\
\text { is my enemy NPN }\end{array}$ & 0.13 & 0.49 & $\begin{array}{l}\text { Number of triads where the focal actor has a negative relationship to } \\
\text { two people who have a positive relationship with each other (NPN). }\end{array}$ \\
\hline 22 & Beta Centrality & 119.06 & 303.24 & Centrality within the combined positive and negative tie networks \\
\hline
\end{tabular}


Table 3

Linear Regression for Individuals' Positive and Negative Ties and Job Performance

\begin{tabular}{|c|c|c|c|c|c|c|c|c|c|c|c|}
\hline & $(1)$ & $(2)$ & (3) & (4) & (5) & (6) & $(7)$ & (8) & (9) & (10) & (11) \\
\hline \multirow[t]{2}{*}{ Org. Tenure } & -0.03 & -0.01 & -0.10 & -0.06 & -0.07 & -0.02 & -0.03 & -0.07 & -0.07 & -0.10 & -0.09 \\
\hline & $(-0.33)$ & $(-0.08)$ & $(-0.98)$ & $(-0.72)$ & $(-0.82)$ & $(-0.29)$ & $(-0.39)$ & $(-0.87)$ & $(-0.81)$ & $(-1.26)$ & $(-0.99)$ \\
\hline \multirow[t]{2}{*}{ Positive Affectivity } & 0.06 & 0.09 & 0.07 & 0.09 & 0.09 & 0.07 & 0.07 & 0.10 & 0.09 & 0.11 & 0.11 \\
\hline & $(0.53)$ & $(0.80)$ & $(0.62)$ & $(0.86)$ & $(0.85)$ & $(0.68)$ & $(0.68)$ & $(0.88)$ & $(0.84)$ & (1.03) & (1.09) \\
\hline \multirow[t]{2}{*}{ Negative Affectivity } & -0.02 & 0.01 & 0.01 & 0.03 & 0.03 & -0.01 & -0.01 & 0.01 & -0.01 & 0.01 & 0.00 \\
\hline & $(-0.23)$ & $(0.14)$ & $(0.08)$ & $(0.38)$ & $(0.34)$ & $(-0.13)$ & $(-0.15)$ & $(0.08)$ & $(-0.08)$ & $(0.12)$ & $(0.01)$ \\
\hline \multirow[t]{2}{*}{ Negative Out Ties } & 0.04 & 0.10 & 0.01 & 0.08 & 0.08 & 0.08 & 0.08 & 0.05 & 0.10 & 0.08 & 0.06 \\
\hline & $(0.27)$ & $(0.85)$ & $(0.07)$ & $(0.67)$ & $(0.70)$ & $(0.75)$ & $(0.78)$ & $(0.55)$ & $(1.13)$ & $(0.89)$ & $(0.62)$ \\
\hline \multirow[t]{2}{*}{ Positive Out Ties } & 0.11 & 0.13 & 0.03 & 0.07 & 0.07 & 0.13 & 0.13 & 0.15 & 0.08 & 0.10 & 0.12 \\
\hline & $(0.35)$ & $(0.61)$ & $(0.10)$ & $(0.34)$ & $(0.32)$ & $(0.62)$ & $(0.60)$ & $(0.68)$ & $(0.37)$ & $(0.46)$ & $(0.51)$ \\
\hline \multirow[t]{2}{*}{ Alters' performance } & -0.09 & -0.18 & -0.10 & -0.18 & -0.18 & -0.21 & -0.21 & -0.22 & -0.23 & -0.23 & -0.24 \\
\hline & $(-0.55)$ & $(-1.06)$ & $(-0.66)$ & $(-1.12)$ & $(-1.16)$ & $(-1.33)$ & $(-1.37)$ & $(-1.40)$ & $(-1.45)$ & $(-1.47)$ & $(-1.45)$ \\
\hline \multirow[t]{2}{*}{ PPP } & 0.05 & -0.02 & 0.08 & 0.01 & 0.01 & 0.00 & 0.01 & -0.01 & 0.05 & 0.02 & 0.00 \\
\hline & $(0.21)$ & $(-0.10)$ & $(0.32)$ & $(0.03)$ & $(0.05)$ & $(0.01)$ & $(0.04)$ & $(-0.06)$ & $(0.22)$ & $(0.11)$ & $(0.00)$ \\
\hline \multirow[t]{2}{*}{ NNN } & $-0.22+$ & $-0.22 *$ & $-0.21+$ & $-0.21^{*}$ & $-0.21^{*}$ & $-0.22 * *$ & $-0.22 *$ & $-0.23^{* *}$ & $-0.19 * *$ & $-0.20 * *$ & $-0.18 * *$ \\
\hline & $(-1.88)$ & $(-2.34)$ & $(-1.95)$ & $(-2.37)$ & $(-2.23)$ & $(-2.92)$ & $(-2.74)$ & $(-3.14)$ & $(-3.09)$ & $(-3.54)$ & $(-2.96)$ \\
\hline \multicolumn{12}{|l|}{ Direct Ties } \\
\hline \multirow{2}{*}{\multicolumn{2}{|c|}{ Negative In Ties N }} & $-0.37 * *$ & & $-0.34 * *$ & $-0.45+$ & $-0.37 * *$ & $-0.45^{*}$ & $-0.50 *$ & $-0.40+$ & $-0.45^{*}$ & $-0.46^{*}$ \\
\hline & & $(-3.10)$ & & $(-2.93)$ & $(-2.02)$ & $(-3.32)$ & $(-2.08)$ & $(-2.46)$ & $(-1.94)$ & $(-2.37)$ & $(-2.39)$ \\
\hline \multirow{2}{*}{\multicolumn{2}{|c|}{ Positive In Ties P }} & & $0.24 *$ & $0.18 *$ & $0.20 *$ & 0.02 & 0.03 & 0.08 & 0.05 & 0.09 & -0.03 \\
\hline & & & $(2.50)$ & $(2.15)$ & $(2.40)$ & $(0.18)$ & $(0.34)$ & $(0.87)$ & $(0.53)$ & $(1.03)$ & $(-0.14)$ \\
\hline \multicolumn{12}{|l|}{ Open Triads } \\
\hline \multirow{2}{*}{\multicolumn{3}{|c|}{ My enemy has a friend NP }} & & & 0.12 & & 0.10 & 0.15 & 0.15 & 0.19 & 0.26 \\
\hline & & & & & $(0.52)$ & & $(0.45)$ & $(0.71)$ & $(0.75)$ & $(1.05)$ & $(1.50)$ \\
\hline \multirow{2}{*}{\multicolumn{3}{|c|}{ My friend has an enemy PN }} & & & & $0.25 *$ & $0.25^{*}$ & $0.32^{*}$ & $0.19+$ & $0.27^{*}$ & $0.31^{*}$ \\
\hline & & & & & & $(2.38)$ & $(2.41)$ & $(2.62)$ & (1.93) & $(2.15)$ & $(2.24)$ \\
\hline \multicolumn{12}{|l|}{ Closed Triads } \\
\hline \multirow{2}{*}{\multicolumn{4}{|c|}{ Friend of my enemy is my friend PNP }} & & & & & $-0.22^{*}$ & & $-0.21^{*}$ & $-0.19+$ \\
\hline & & & & & & & & $(-2.12)$ & & $(-2.12)$ & $(-1.99)$ \\
\hline \multirow{2}{*}{\multicolumn{4}{|c|}{ Enemy of my friend is my enemy NPN }} & & & & & & $-0.20 *$ & $-0.19+$ & $-0.22 *$ \\
\hline & & & & & & & & & $(-2.23)$ & $(-2.03)$ & $(-2.03)$ \\
\hline \multicolumn{12}{|l|}{ Whole Network } \\
\hline \multirow{2}{*}{\multicolumn{3}{|c|}{ Beta Centrality }} & & & & & & & & & 0.20 \\
\hline & & & & & & & & & & & $(0.89)$ \\
\hline Constant & $4.27 * *$ & $4.28 * *$ & $3.95^{* *}$ & $4.03^{* *}$ & $4.01^{* *}$ & $4.26^{*}$ & $4.24 * *$ & $4.12^{* *}$ & $4.17^{* *}$ & $4.06^{* *}$ & $3.95^{* *}$ \\
\hline $\mathrm{F}$ & $4.10^{* *}$ & $4.24 * *$ & $4.49 * *$ & $7.68 * *$ & $7.69 * *$ & $8.75^{* *}$ & $6.90 * *$ & $19.58^{* *}$ & $18.52 * *$ & $55.11 * *$ & $49.66^{* *}$ \\
\hline r-squared & 0.22 & 0.33 & 0.26 & 0.36 & 0.36 & 0.39 & 0.40 & 0.43 & 0.42 & 0.45 & 0.46 \\
\hline adjusted r-squared & 0.07 & 0.20 & 0.11 & 0.21 & 0.20 & 0.25 & 0.24 & 0.27 & 0.26 & 0.28 & 0.28 \\
\hline
\end{tabular}

Note: $\mathrm{N}=$ 83. Dummy variables for building were included in all models; the results were not reported here to conserve space. Standardized beta coefficients; t-statistics in parentheses. Standard errors clustered around supervisor $(\mathrm{n}=32)$ are robust. $+\mathrm{p}<.1$; ${ }^{*} \mathrm{p}<.05 ;{ }^{* *} \mathrm{p}<.01$; two-tailed. 
Open Triad

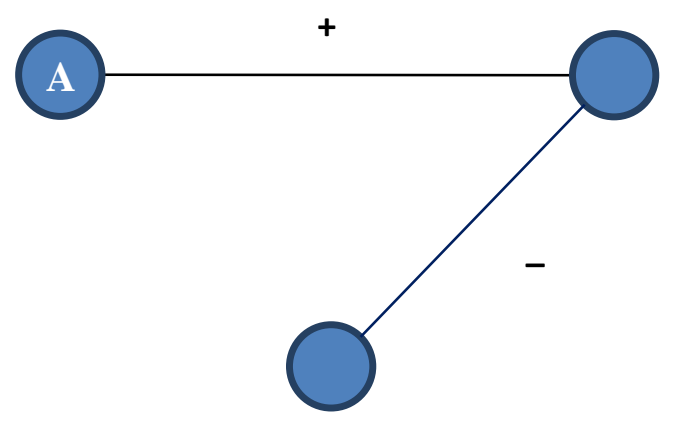

Closed Triad

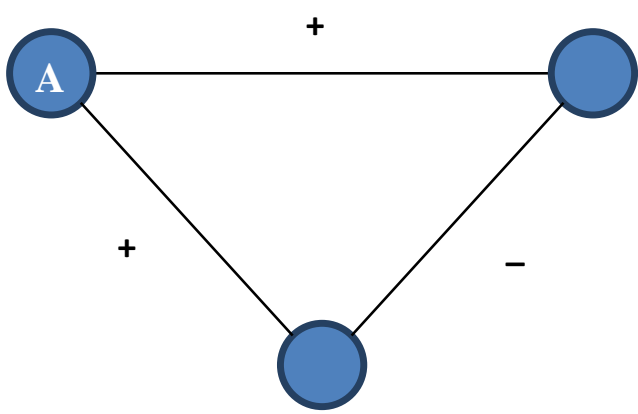

Figure 1: Examples of how the focal actor (A) can be embedded in an open or closed triad.

Focal person " $A$ " is two links removed along the shorted path from the negative tie in both triads (i.e., A is at a social distance of two from the negative tie). What differs is whether A has a positive relationship with one or both of the individuals involved in the negative tie.

Note: Circles or nodes are people; “+” refers to a positive relationship; “-“ refers to a negative relationship 

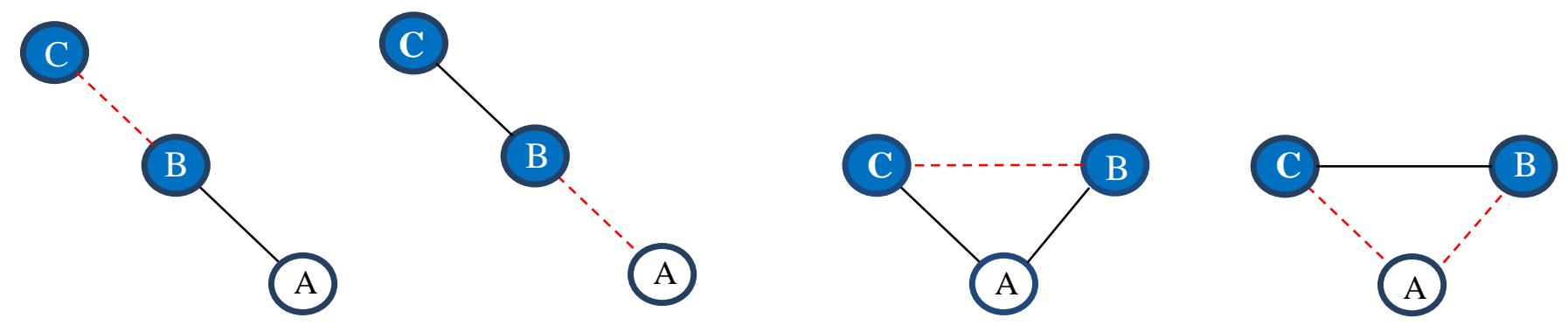

$\begin{array}{lll}\text { 1. Open Triad (PN): } & \text { 2. Open Triad (NP): } & \text { 3. Closed Triad (PNP): } \\ \begin{array}{l}\text { Focal actor A is } \\ \text { positively tied to B, who }\end{array} & \text { Focal actor A is negatively } & \text { Focal actor A is positively } \\ \text { has a negative tie to C. } & \text { positive tie to C } & \text { connected to parties B and } \\ & & \text { C who are connected by a } \\ & & \text { negative tie. }\end{array}$

4. Closed Triad (NPN):

Focal actor $\mathrm{A}$ is

negatively connected to parties $\mathrm{B}$ and $\mathrm{C}$ who are connected by a positive tie.

Negative tie

Positive tie

Figure 2: Examples of how the focal actor (A) can be directly and indirectly related to negative ties at different social distances. 


\section{Appendix A}

Supervisor-Rated Job Performance Items (Tsui, 1984)

1. This employee is performing his/her total job the way I would like it performed

2. I am satisfied with the total contribution this employee has made to the organization

3. I enjoy working with this employee

4. This employee has met all of my expectations in terms of his/her roles and responsibilities

5. I respect this employee's judgment

6. I believe that this employee will pitch in and help whenever I ask

7. If I had my way, I would change the manner in which this person is doing his/her job (reverse scored).

(Cronbach's $\alpha=.88)$ 


\begin{tabular}{ccc}
\multicolumn{3}{c}{ Appendix B } \\
Descriptive Statistics on All Incoming and Outgoing Positive \\
and Negative Tie Matrices $(N=154)$ \\
\\
& Positive Ties & Negative Ties \\
\cline { 2 - 3 } \# of Observations & 23562 & 23562 \\
Density & 0.014 & 0.004 \\
S.D. & 0.117 & 0.065 \\
Sum & 327 & 101 \\
\end{tabular}


Appendix C

Frequency table for all network variables of interest $(\mathrm{N}=154)$

\begin{tabular}{ccccccccc} 
Count & $\begin{array}{c}\text { Positive } \\
\text { incoming } \\
\text { ties (P) }\end{array}$ & $\begin{array}{c}\text { Negative } \\
\text { incoming } \\
\text { ties (N) }\end{array}$ & $\begin{array}{c}\text { Open } \\
\text { Triad } \\
(\mathrm{PN})\end{array}$ & $\begin{array}{c}\text { Open } \\
\text { Triad } \\
(\mathrm{NP})\end{array}$ & $\begin{array}{c}\text { Closed } \\
\text { Triad } \\
(\mathrm{NPN})\end{array}$ & $\begin{array}{c}\text { Closed } \\
\text { Triad } \\
(\mathrm{PNP})\end{array}$ & $\begin{array}{c}\text { Closed } \\
\text { Triad } \\
(\mathrm{NNN})\end{array}$ & $\begin{array}{c}\text { Closed } \\
\text { Triad } \\
(\mathrm{PPP})\end{array}$ \\
\hline 0 & 32 & 95 & 90 & 112 & 143 & 139 & 146 & 96 \\
\hline 1 & 29 & 30 & 47 & 25 & 3 & 10 & 6 & 18 \\
2 & 39 & 18 & 15 & 11 & 7 & 5 & 2 & 19 \\
3 & 24 & 9 & 1 & 5 & 1 & - & - & 3 \\
4 & 14 & 2 & 1 & 1 & - & - & - & 4 \\
5 & 9 & - & - & - & - & - & - & 4 \\
6 & 4 & - & - & - & - & - & - & 3 \\
7 & 1 & - & - & - & - & - & - & 2 \\
8 & 2 & - & - & - & - & - & - & 2 \\
$9+$ & 0 & & & & & & & 3 \\
\hline Total & 154 & 154 & 154 & 154 & 154 & 154 & 154 & 154 \\
\hline
\end{tabular}


Appendix D

Linear Regression for Individuals' Positive and Negative Ties and Job Performance (no clusters)

\begin{tabular}{|c|c|c|c|c|c|c|c|c|c|c|c|}
\hline & $(1)$ & $(2)$ & (3) & (4) & (5) & $(6)$ & $(7)$ & $(8)$ & $(9)$ & $(10)$ & $(11)$ \\
\hline Org. Tenure & $\begin{array}{c}-0.07 \\
(-0.72)\end{array}$ & $\begin{array}{c}-0.05 \\
(-0.53)\end{array}$ & $\begin{array}{c}-0.14 \\
(-1.13)\end{array}$ & $\begin{array}{c}-0.10 \\
(-0.89)\end{array}$ & $\begin{array}{c}-0.11 \\
(-0.96)\end{array}$ & $\begin{array}{c}-0.06 \\
(-0.54)\end{array}$ & $\begin{array}{c}-0.07 \\
(-0.60)\end{array}$ & $\begin{array}{c}-0.10 \\
(-0.87)\end{array}$ & $\begin{array}{c}-0.10 \\
(-0.86)\end{array}$ & $\begin{array}{c}-0.12 \\
(-1.10)\end{array}$ & $\begin{array}{c}-0.11 \\
(-0.99)\end{array}$ \\
\hline Positive Affectivity & $\begin{array}{c}0.07 \\
(0.69)\end{array}$ & $\begin{array}{c}0.09 \\
(1.00)\end{array}$ & $\begin{array}{c}0.08 \\
(0.74)\end{array}$ & $\begin{array}{c}0.09 \\
(1.01)\end{array}$ & $\begin{array}{c}0.09 \\
(1.03)\end{array}$ & $\begin{array}{c}0.07 \\
(0.75)\end{array}$ & $\begin{array}{c}0.07 \\
(0.77)\end{array}$ & $\begin{array}{c}0.09 \\
(1.00)\end{array}$ & $\begin{array}{c}0.09 \\
(0.93)\end{array}$ & $\begin{array}{c}0.11 \\
(1.13)\end{array}$ & $\begin{array}{c}0.11 \\
(1.19)\end{array}$ \\
\hline Negative Affectivity & $\begin{array}{c}-0.02 \\
(-0.19)\end{array}$ & $\begin{array}{c}0.01 \\
(0.14)\end{array}$ & $\begin{array}{c}0.01 \\
(0.08)\end{array}$ & $\begin{array}{c}0.04 \\
(0.36)\end{array}$ & $\begin{array}{c}0.03 \\
(0.32)\end{array}$ & $\begin{array}{c}-0.01 \\
(-0.12)\end{array}$ & $\begin{array}{l}-0.01 \\
(-0.15)\end{array}$ & $\begin{array}{c}0.00 \\
(0.04)\end{array}$ & $\begin{array}{c}-0.01 \\
(-0.10)\end{array}$ & $\begin{array}{c}0.01 \\
(0.07)\end{array}$ & $\begin{array}{c}-0.00 \\
(-0.02)\end{array}$ \\
\hline Negative Out Ties & $\begin{array}{c}0.07 \\
(0.46)\end{array}$ & $\begin{array}{c}0.13 \\
(1.04)\end{array}$ & $\begin{array}{c}0.03 \\
(0.23)\end{array}$ & $\begin{array}{c}0.10 \\
(0.82)\end{array}$ & $\begin{array}{c}0.10 \\
(0.84)\end{array}$ & $\begin{array}{c}0.10 \\
(0.88)\end{array}$ & $\begin{array}{c}0.10 \\
(0.89)\end{array}$ & $\begin{array}{c}0.08 \\
(0.72)\end{array}$ & $\begin{array}{c}0.12 \\
(1.16)\end{array}$ & $\begin{array}{c}0.10 \\
(0.96)\end{array}$ & $\begin{array}{c}0.08 \\
(0.78)\end{array}$ \\
\hline Positive Out Ties & $\begin{array}{c}0.11 \\
(0.49)\end{array}$ & $\begin{array}{c}0.14 \\
(0.73)\end{array}$ & $\begin{array}{c}0.03 \\
(0.14)\end{array}$ & $\begin{array}{c}0.08 \\
(0.37)\end{array}$ & $\begin{array}{c}0.08 \\
(0.36)\end{array}$ & $\begin{array}{c}0.14 \\
(0.68)\end{array}$ & $\begin{array}{c}0.14 \\
(0.67)\end{array}$ & $\begin{array}{c}0.15 \\
(0.77)\end{array}$ & $\begin{array}{c}0.10 \\
(0.47)\end{array}$ & $\begin{array}{c}0.12 \\
(0.57)\end{array}$ & $\begin{array}{c}0.14 \\
(0.67)\end{array}$ \\
\hline Alters' performance & $\begin{array}{c}-0.16 \\
(-1.20)\end{array}$ & $\begin{array}{l}-0.23+ \\
(-1.86)\end{array}$ & $\begin{array}{c}-0.17 \\
(-1.37)\end{array}$ & $\begin{array}{l}-0.24^{*} \\
(-2.00)\end{array}$ & $\begin{array}{l}-0.24^{*} \\
(-2.01)\end{array}$ & $\begin{array}{l}-0.25^{*} \\
(-2.20)\end{array}$ & $\begin{array}{l}-0.26^{*} \\
(-2.22)\end{array}$ & $\begin{array}{l}-0.26^{*} \\
(-2.28)\end{array}$ & $\begin{array}{l}-0.27^{*} \\
(-2.35)\end{array}$ & $\begin{array}{l}-0.28^{*} \\
(-2.40)\end{array}$ & $\begin{array}{l}-0.28 * \\
(-2.36)\end{array}$ \\
\hline PPP & $\begin{array}{c}0.07 \\
(0.33)\end{array}$ & $\begin{array}{c}-0.01 \\
(-0.07)\end{array}$ & $\begin{array}{c}0.10 \\
(0.43)\end{array}$ & $\begin{array}{c}0.01 \\
(0.07)\end{array}$ & $\begin{array}{c}0.02 \\
(0.08)\end{array}$ & $\begin{array}{c}0.01 \\
(0.05)\end{array}$ & $\begin{array}{c}0.01 \\
(0.06)\end{array}$ & $\begin{array}{c}-0.01 \\
(-0.04)\end{array}$ & $\begin{array}{c}0.04 \\
(0.22)\end{array}$ & $\begin{array}{c}0.02 \\
(0.11)\end{array}$ & $\begin{array}{c}0.00 \\
(0.00)\end{array}$ \\
\hline NNN & $\begin{array}{l}-0.21+ \\
(-1.72)\end{array}$ & $\begin{array}{l}-0.20^{*} \\
(-2.15)\end{array}$ & $\begin{array}{l}-0.19+ \\
(-1.83)\end{array}$ & $\begin{array}{l}-0.19 * \\
(-2.24)\end{array}$ & $\begin{array}{l}-0.19 * \\
(-2.15)\end{array}$ & $\begin{array}{c}-0.20 * * \\
(-2.85)\end{array}$ & $\begin{array}{c}-0.20 * * \\
(-2.73)\end{array}$ & $\begin{array}{c}-0.21^{* *} \\
(-3.12)\end{array}$ & $\begin{array}{l}-0.18^{*} \\
(-2.64)\end{array}$ & $\begin{array}{c}-0.19 * * \\
(-2.97)\end{array}$ & $\begin{array}{l}-0.17^{*} \\
(-2.56)\end{array}$ \\
\hline Direct Ties & & & & & & & & & & & \\
\hline Negative In Ties $\mathrm{N}$ & & $\begin{array}{c}-0.37^{* *} \\
(-3.76)\end{array}$ & & $\begin{array}{c}-0.35 * * \\
(-3.48)\end{array}$ & $\begin{array}{l}-0.42 * \\
(-2.05)\end{array}$ & $\begin{array}{c}-0.36^{* *} \\
(-3.75)\end{array}$ & $\begin{array}{l}-0.43^{*} \\
(-2.16)\end{array}$ & $\begin{array}{l}-0.46^{*} \\
(-2.41)\end{array}$ & $\begin{array}{l}-0.38+ \\
(-1.89)\end{array}$ & $\begin{array}{l}-0.42 * \\
(-2.15)\end{array}$ & $\begin{array}{l}-0.43^{*} \\
(-2.19)\end{array}$ \\
\hline Positive In Ties $\mathrm{P}$ & & & $\begin{array}{l}0.23^{*} \\
(2.21)\end{array}$ & $\begin{array}{l}0.18+ \\
(1.85)\end{array}$ & $\begin{array}{l}0.19+ \\
(1.96)\end{array}$ & $\begin{array}{c}0.00 \\
(0.05)\end{array}$ & $\begin{array}{c}0.02 \\
(0.15)\end{array}$ & $\begin{array}{c}0.06 \\
(0.58)\end{array}$ & $\begin{array}{c}0.03 \\
(0.27)\end{array}$ & $\begin{array}{c}0.07 \\
(0.68)\end{array}$ & $\begin{array}{c}-0.04 \\
(-0.24)\end{array}$ \\
\hline Open Triads & & & & & & & & & & & \\
\hline My enemy has a friend NP & & & & & $\begin{array}{c}0.09 \\
(0.40)\end{array}$ & & $\begin{array}{c}0.07 \\
(0.37)\end{array}$ & $\begin{array}{c}0.11 \\
(0.59)\end{array}$ & $\begin{array}{c}0.11 \\
(0.59)\end{array}$ & $\begin{array}{c}0.14 \\
(0.82)\end{array}$ & $\begin{array}{c}0.21 \\
(1.17)\end{array}$ \\
\hline My friend has an enemy PN & & & & & & $\begin{array}{c}0.26 * * \\
(2.95)\end{array}$ & $\begin{array}{c}0.26 * * \\
(2.95)\end{array}$ & $\begin{array}{c}0.33 * * \\
(3.36)\end{array}$ & $\begin{array}{l}0.22^{*} \\
(2.40)\end{array}$ & $\begin{array}{c}0.29 * * \\
(2.84)\end{array}$ & $\begin{array}{l}0.32 * * \\
(2.92)\end{array}$ \\
\hline Closed Triads & & & & & & & & & & & \\
\hline Friend of my enemy is my friend PNP & & & & & & & & $\begin{array}{l}-0.20^{*} \\
(-2.39)\end{array}$ & & $\begin{array}{l}-0.19^{*} \\
(-2.21)\end{array}$ & $\begin{array}{l}-0.18^{*} \\
(-2.06)\end{array}$ \\
\hline Enemy of my friend is my enemy NPN & & & & & & & & & $\begin{array}{l}-0.17+ \\
(-1.90)\end{array}$ & $\begin{array}{l}-0.15^{+} \\
(-1.76)\end{array}$ & $\begin{array}{l}-0.18+ \\
(-1.94)\end{array}$ \\
\hline Whole Network & & & & & & & & & & & \\
\hline Beta Centrality & & & & & & & & & & & $\begin{array}{c}0.18 \\
(1.06)\end{array}$ \\
\hline Constant & $4.24^{* *}$ & $4.25^{* *}$ & $3.95^{* *}$ & $4.03 * *$ & $4.01^{* *}$ & $4.29 * *$ & $4.28 * *$ & $4.17 * *$ & $4.20^{* *}$ & $4.10^{* *}$ & $3.97^{* *}$ \\
\hline $\mathrm{F}$ & $3.08 * *$ & $3.60 * *$ & $3.33 * *$ & $4.06^{* *}$ & $3.90 * *$ & $4.37 * *$ & $4.27 * *$ & $4.89 * *$ & $6.56^{* *}$ & $6.93 * *$ & $7.02 * *$ \\
\hline r-squared & 0.24 & 0.36 & 0.28 & 0.38 & 0.39 & 0.43 & 0.43 & 0.46 & 0.44 & 0.47 & 0.48 \\
\hline adjusted r-squared & 0.11 & 0.24 & 0.14 & 0.26 & 0.25 & 0.30 & 0.29 & 0.32 & 0.30 & 0.33 & 0.33 \\
\hline
\end{tabular}

Note: $\mathrm{N}=89$. Dummy variables for building were included in all models, the results were not reported here to conserve space. Standardized beta coefficients; t-statistics in parentheses. Standard errors are robust. ${ }^{+p}<.1 ;{ }^{*} \mathrm{p}<.05 ; * * \mathrm{p}<.01$; two-tailed. 
Appendix E

Pearson Correlations for all variables

\begin{tabular}{|c|c|c|c|c|c|c|c|c|c|}
\hline & & $\mathrm{n}$ & 1. & 2. & 3. & 4. & 5. & 6. & 7. \\
\hline 1. & Performance & 90 & $(0.88)$ & & & & & & \\
\hline 2. & Building 1 & 154 & $-.21^{*}$ & & & & & & \\
\hline 3. & Building 2 & 154 & -.21 & $-.27^{* *}$ & & & & & \\
\hline 4. & Building 3 & 154 & -.04 & -.15 & -.15 & & & & \\
\hline 5. & Building 4 & 154 & $.28^{* *}$ & $-.20^{*}$ & $-.20^{*}$ & -.11 & & & \\
\hline 6. & Building 5 & 154 & .14 & $-.35^{* *}$ & $-.35^{* *}$ & $-.19^{*}$ & $-.25^{* *}$ & & \\
\hline 7. & Building 6 & 154 & .16 & -.14 & -.14 & -.08 & -.10 & $-.17^{*}$ & \\
\hline 8. & Org. Tenure & 154 & -.06 & .09 & -.05 & -.11 & $-.23^{* *}$ & .15 & .09 \\
\hline 9. & Positive Affectivity & 153 & .04 & .08 & .02 & -.01 & .02 & -.14 & .09 \\
\hline 10. & Negative Affectivity & 153 & -.08 & -.01 & -.13 & .09 & -.06 & .16 & -.07 \\
\hline 11. & Negative Out Ties & 154 & -.03 & $.16^{*}$ & -.11 & -.06 & .08 & -.04 & -.06 \\
\hline 12. & Positive Out Ties & 154 & .16 & -.10 & -.02 & -.05 & .14 & .11 & -.13 \\
\hline 13. & Alters' performance & 154 & -.06 & -.04 & .04 & -.01 & .06 & -.05 & .01 \\
\hline 14. & PPP & 154 & $.23^{*}$ & -.07 & -.06 & -.10 & $.22^{* *}$ & .08 & -.11 \\
\hline 15. & NNN & 154 & $-.24^{*}$ & .15 & -.01 & -.06 & -.02 & -.05 & -.06 \\
\hline 16. & Negative In Ties & 154 & $-.36^{* *}$ & $.18^{*}$ & -.11 & -.10 & -.07 & .03 & .01 \\
\hline 17. & Friend In Ties & 154 & $.26^{*}$ & -.13 & -.02 & $-.17^{*}$ & $.20^{*}$ & .13 & -.08 \\
\hline 18. & My enemy has a friend NP & 154 & $-.27^{*}$ & .10 & $-.17^{*}$ & -.05 & -.01 & .06 & .07 \\
\hline 19. & My friend has an enemy PN & 154 & .21 & .15 & -.05 & -.12 & .09 & -.06 & -.06 \\
\hline 20. & $\begin{array}{l}\text { Friend of my enemy is my friend } \\
\text { PNP }\end{array}$ & 154 & .03 & -.05 & -.05 & .03 & $.17^{*}$ & .00 & -.08 \\
\hline 21. & $\begin{array}{l}\text { Enemy of my friend is my enemy } \\
\text { NPN }\end{array}$ & 154 & $-.36^{* *}$ & .09 & .02 & -.08 & .02 & -.03 & -.07 \\
\hline 22. & Beta Centrality & 154 & $.33^{* *}$ & -.12 & $-.16^{*}$ & -.11 & $.43^{* *}$ & .09 & $-.16^{*}$ \\
\hline
\end{tabular}

Note. Scale reliability scores are in parentheses where applicable (Cronbach's $\alpha$ ).

$+p<.1{ }^{*} p<.05 . * * p<.01$; two-tailed. 
Appendix E Continued

Pearson Correlations for all variables

9.

10.

11.

12.

13.

14.

15.

16.

17.

18.

19.

20. 21.

Positive Affectivity

Negative Affectivity

Negative Out Ties

Positive Out Ties

Alters' performance

PPP

NNN

Negative In Ties

Friend In Ties

My enemy has a friend NP

$\begin{array}{ccc}.03 & (0.84) & \\ -.01 & -.24^{* *} & (0.84) \\ -.01 & -.15 & .27^{* *} \\ .11 & .03 & -.02\end{array}$

$\begin{array}{lll}.11 & .03 & -.02 \\ .06 & .06 & .00\end{array}$

$\begin{array}{rrr}.06 & .06 & .00 \\ .06 & .02 & -.06 \\ -.05 & -.04 & .07\end{array}$

$\begin{array}{lll}. .05 & -.04 & .07\end{array}$

$.31^{* *}$

$.46^{* *}$

$.15 \quad .83^{* *}$

$\begin{array}{cc}.15 & .83 \\ .46^{* *} & .07\end{array}$

$\begin{array}{lll}.12 & .02 & .15 \\ .25^{* *} & .02 & -.03\end{array}$

My friend has an enemy PN

$.10 \quad-.01$

$-.03$

.11
$.16^{*}$
.10

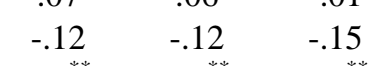

My friend has an enemy PN

friend PNP

Enemy of my friend is my

enemy NPN

$.07 \quad .07$

.15

$\begin{array}{lll}.10 & -.10 & -.08\end{array}$

$.29^{* * *}$

$-.11$

.05
-.02

$\begin{array}{ll}-.02 & -.06\end{array}$

$-.08 \quad .07$

13

03

$.12 \quad .17^{*}$

.02

.05

$.85^{* *}$

$\begin{array}{lll}-.08 & .07 \quad .13\end{array}$

Beta Centrality

$\begin{array}{lll}-.12 & .00 \quad .10\end{array}$

.03

$.11 \quad .10$

$.04 \quad-.02$

$-.05$

$-.09$

$.10 \quad .13$

$\begin{array}{lll}-.07 & -.08 & -.02\end{array}$

$-.02 \quad .12$

$-.05 \quad .35^{* *}$

.06

Note. Scale reliability scores are in parentheses where applicable (Cronbach's $\alpha$ ).

$+p<.1{ }^{*} p<.05 .{ }^{* *} p<.01$; two-tailed. 


\section{Appendix F}

Post-hoc analyses. A key question raised by our findings was whether individuals are intentionally befriending those in conflict in order to extract benefits from others' pain, as Simmel (1950) might suggest. That is, if ego sees two alters in a negative tie, will ego choose to befriend one, possibly with the intention to extract resources from that dependent other? To examine this question, we took advantage of a unique feature of our data set to shed some light on the question of intentionality. The organization had encountered significant issues with turnover in the year prior to the data collection, partly due to the worst downturn in the economy of the state in which it was located since the Great Depression, which prevented the granting of raises. Hence, approximately $20 \%$ of the organization had less than a year of tenure. While we did not know the age of the positive and negative ties, we did know each individual's tenure in the organization, which told us each tie's maximum potential age (e.g., if ego's tenure was 1 year and alter's tenure was 2 years, they could only have had a relationship for a maximum of 1 year). We used this to see whether the direct positive tie was newer than the alters' negative tie. We formed three count variables (one where the positive tie in the open triad is potentially older than the negative tie, one where it is younger, and one where it is equal in maximum possible age). Note that these variables make the following assumptions: the relationship begins immediately; there was no relationship between the individuals prior to employment at the company; and a tie did not change valence from positive to negative, or vice versa, at any point.

We found that 39\% of the open triads had newer positive ties, 33\% had older positive ties, and the remaining $28 \%$ were of the same maximum age. Upon entering these three count variables in the regression model in place of the open triad variable, we found that these triads were not significantly related to job performance (full results not reported, but available from the 
authors). This result might suggest that intentionality was not a factor in how these triads formed, but we must temper any conclusions based on this analysis with the limiting assumptions of our measures mentioned above. We wanted to examine two essential motivations for ego in these open triads. First, it might be that ego senses that there is an opportunity to exploit an alter involved in a negative tie (Simmel, 1950); however it is also possible that the alter is involved in a negative tie, sees a new organizational member as a new possible ally, and decides to provide benefits to ego to lure them into a friendship (e.g., Smith, 1989). While we cannot sort out these contrasting possibilities with our data, we think that the question of intentionality in open triad tie formation is important (e.g., Brief et al., 2005), and worthy of future research to better understand how network evolution is related to performance outcomes. 
Direct and Indirect Negative Ties and Individual Performance

\begin{abstract}
Author Note
Joshua E. Marineau, Department of Management and Marketing, North Dakota State University; Giuseppe (Joe) Labianca, Department of Management, University of Kentucky; Gerald C. Kane, Department of Information Systems, Boston College.

The authors thank Dan Brass, Steve Borgatti, Ginny Kidwell, Ajay Mehra, Kristin Scott, Scott Soltis and other members of the LINKS Center for Social Network Analysis at the University of Kentucky for their help and guidance on previous versions of this paper. This material is based upon work supported by the National Science Foundation Graduate Research Fellowship under Grant No. 0953285.

Correspondence concerning this paper should be addressed to Joshua Marineau, Department of Management and Marketing, North Dakota State University, Fargo, ND 58102. E-mail: joshmarineau@gmail.com
\end{abstract}

